\title{
Last Interglacial climate and sea-level evolution from a coupled ice sheet-climate model
}

\author{
Heiko Goelzer ${ }^{1, a}$, Philippe Huybrechts ${ }^{1}$, Marie-France Loutre ${ }^{2}$, and Thierry Fichefet ${ }^{2}$ \\ ${ }^{1}$ Earth System Sciences \& Departement Geografie, Vrije Universiteit Brussel, Brussels, Belgium \\ ${ }^{2}$ Université catholique de Louvain, Earth and Life Institute, Georges Lemaître Centre for Earth and Climate \\ Research (TECLIM), Louvain-la-Neuve, Belgium \\ anow at: Institute for Marine and Atmospheric Research, Utrecht University, Utrecht, the Netherlands \\ Correspondence to: Heiko Goelzer (h.goelzer@uu.nl, heiko.goelzer@vub.ac.be)
}

Received: 22 November 2015 - Published in Clim. Past Discuss.: 18 January 2016

Revised: 10 October 2016 - Accepted: 10 November 2016 - Published: 15 December 2016

\begin{abstract}
As the most recent warm period in Earth's history with a sea-level stand higher than present, the Last Interglacial (LIG, $\sim 130$ to $115 \mathrm{kyr} \mathrm{BP}$ ) is often considered a prime example to study the impact of a warmer climate on the two polar ice sheets remaining today. Here we simulate the Last Interglacial climate, ice sheet, and sea-level evolution with the Earth system model of intermediate complexity LOVECLIM v.1.3, which includes dynamic and fully coupled components representing the atmosphere, the ocean and sea ice, the terrestrial biosphere, and the Greenland and Antarctic ice sheets. In this setup, sea-level evolution and climate-ice sheet interactions are modelled in a consistent framework.

Surface mass balance change governed by changes in surface meltwater runoff is the dominant forcing for the Greenland ice sheet, which shows a peak sea-level contribution of $1.4 \mathrm{~m}$ at $123 \mathrm{kyr} \mathrm{BP}$ in the reference experiment. Our results indicate that ice sheet-climate feedbacks play an important role to amplify climate and sea-level changes in the Northern Hemisphere. The sensitivity of the Greenland ice sheet to surface temperature changes considerably increases when interactive albedo changes are considered. Southern Hemisphere polar and sub-polar ocean warming is limited throughout the Last Interglacial, and surface and sub-shelf melting exerts only a minor control on the Antarctic sea-level contribution with a peak of $4.4 \mathrm{~m}$ at $125 \mathrm{kyr} \mathrm{BP}$. Retreat of the Antarctic ice sheet at the onset of the LIG is mainly forced by rising sea level and to a lesser extent by reduced ice shelf viscosity as the surface temperature increases. Global sea level shows a peak of $5.3 \mathrm{~m}$ at $124.5 \mathrm{kyr} \mathrm{BP}$, which includes a mi-
\end{abstract}

nor contribution of $0.35 \mathrm{~m}$ from oceanic thermal expansion. Neither the individual contributions nor the total modelled sea-level stand show fast multi-millennial timescale variations as indicated by some reconstructions.

\section{Introduction}

The climate and sea-level evolution of past warm periods in the history of the Earth can give important insights into expected changes in the future. The Last Interglacial (LIG) in particular is often considered as a prime candidate for a potential, albeit limited, analogue for a warmer future world, due to a wealth of available reconstructions of climate and sea level for this period $\sim 130-115$ thousand years (kyr) ago (e.g. Dutton et al., 2015). Problems for the direct comparison between LIG and future climates arise mainly from the different forcing responsible for the warming, which can be ascribed to orbital variations during the LIG and to elevated levels of greenhouse gases in the future. During the LIG, global mean annual surface temperature is thought to have been 1 to $2{ }^{\circ} \mathrm{C}$ higher and peak global annual sea surface temperatures $0.7^{\circ} \mathrm{C} \pm 0.6^{\circ} \mathrm{C}$ higher than during the pre-industrial period (e.g. Turney and Jones, 2010; McKay et al., 2011), with the caveat that warmest phases were assumed globally synchronous in these data syntheses (Masson-Delmotte et al., 2013). These numbers are largely confirmed by a recent compilation which resolves the temporal temperature evolution (Capron et al., 2014). Due to polar amplification, high-latitude surface temperatures, when av- 
eraged over several thousand years, were at least $2{ }^{\circ} \mathrm{C}$ higher than present (Masson-Delmotte et al., 2013) and were up to $5^{\circ} \mathrm{C}$ higher over the ice sheets (EPICA community members, 2004; Masson-Delmotte et al., 2015). These high temperatures had severe consequences for the evolution of the ice sheets at the onset and during the LIG as evidenced in large variations in sea level (Rohling et al., 2014; Grant et al., 2012). Coming out of the penultimate glaciation with a sea-level depression of up to $130 \mathrm{~m}$, the global sea level peaked during the LIG, estimated at 5.5 to $9 \mathrm{~m}$ higher than today (Dutton and Lambeck, 2012; Kopp et al., 2009, 2013), with a current best estimate of $6 \mathrm{~m}$ above the present level (Masson-Delmotte et al., 2013).

A higher-than-present sea-level stand almost certainly implies a complete melting of the Laurentide and Fennoscandian ice sheets and a contribution from the Greenland ice sheet (GrIS), from the Antarctic ice sheet (AIS), or from both. However, ice sheet retreat should not be assumed synchronous in the Northern and Southern hemispheres and between individual ice sheets. Fluctuations in global sea-level during the LIG period (Thompson et al., 2011; Kopp et al., 2013) could be a consequence of differences in the timing of retreat and regrowth between the GrIS and AIS.

Because direct evidence for an AIS contribution to the LIG sea-level high stand is thus far elusive, support for a contribution from the AIS is usually given as a residual of total sealevel stand minus contributions from the GrIS, thermal expansion (THXP), and glaciers and small ice caps. This illustrates that the attribution problem is so far largely underdetermined. It appears that the lower bound of $5.5 \mathrm{~m}$ for the LIG sea-level high stand (Dutton and Lambeck, 2012; Kopp et al., 2013) could be fully explained by maximum values given in the IPCC AR5 (Masson-Delmotte et al., 2013) for the contributions of the GrIS (1.4-4.3 m), glaciers and small ice caps $(0.42 \pm 0.11 \mathrm{~m})$, and THXP $(0.4 \pm 0.3 \mathrm{~m})$ combined. However, assuming central estimates for all individual components and the total would indicate an Antarctic contribution of $\sim 3 \mathrm{~m}$, which would be in line with the contribution estimated for a collapse of the West Antarctic ice sheet (WAIS) alone (Bamber et al., 2009). An Antarctic component is generally assumed to have foremost come from the WAIS, which is thought to be vulnerable due to its marine-based character. It is often speculated to be sensitive to ocean warming and increased sub-shelf melting (e.g. Duplessy et al., 2007; Holden et al., 2010), possibly caused by the interhemispheric seesaw effect (Stocker, 1998). However, a combination of partial WAIS collapse and some East Antarctic ice sheet (EAIS) retreat is also a possibility due to the large size of the latter. High-end estimates of sea-level change can only be reconciled with an additional EAIS contribution, supposedly from marine-based sectors in the Wilkes and Aurora basins (Pollard et al., 2015; DeConto and Pollard, 2016). One issue complicating the residual argument is the aforementioned possibility of different timing of the GrIS and AIS contributions. Indirect evidence of a WAIS reduction or collapse may come from climate modelling studies that attempt to explain stableisotope ratios from ice (core) records (Holden et al., 2010; Steig et al., 2015).

The GrIS evolution is somewhat better constrained than the AIS evolution by ice core records both in the central part (GRIP, NGRIP, NEEM) and at the periphery (Dye-3, Camp Century), even if interpretation of the lower parts of the records remains ambiguous. To this date, none of the Greenland ice cores shows continuous and undisturbed information back in time through the LIG and into the penultimate glacial maximum. The relatively high temperatures during the LIG as reconstructed from the folded lower parts of the NEEM ice core (NEEM community members, 2013; Landais et al., 2016) seem to be incompatible with the general view that the ice sheet lost rather little volume during the LIG (e.g. Robinson et al., 2011; Colville et al., 2011). Several studies have therefore attempted to identify possible biases in the NEEM reconstructions (e.g. van de Berg et al., 2013; Merz et al., 2014, 2016; Sjolte and Hoffmann, 2014; Steen-Larsen et al., 2014; Masson-Delmotte et al., 2015; Pedersen et al., 2016). Furthermore, the minimum extent and margin position of the north-eastern part of the ice sheet is not well constrained, leaving room for alternative retreat scenarios (e.g. Born and Nisancioglu, 2012).

Modelling studies of the GrIS for the entire LIG period so far often use parameterised representations of the climate forcing (e.g. Huybrechts, 2002), forcing based on time slice climate experiments (e.g. Born and Nisancioglu, 2012; Stone et al., 2013) or asynchronous coupling (Helsen et al., 2013), while full coupling between ice and climate models is still a challenge and limited to models of intermediate complexity (e.g. Robinson et al., 2011). Ice sheet modelling studies with specific focus on the AIS during the LIG are rare due to the aforementioned lack of climate and geomorphological constraints for that period. However, some results on the AIS during the LIG have been presented in studies with main focus on other time periods (e.g. Huybrechts, 2002) or with interest on longer timescales (e.g. Pollard and DeConto, 2009; de Boer et al., 2013, 2014). A recent study by DeConto and Pollard (2016) utilises simulations of the AIS during the LIG to constrain future sea-level projections.

Despite recent advances (e.g. Capron et al., 2014), the fundamental shortcoming at present for improving modelled constraints on the LIG ice sheet contribution to sea level with physical models is the sparse information on LIG polar climate and oceanic conditions. Consequently, our effort is directed towards studying key mechanisms and feedback processes in the coupled climate-ice sheet system during the LIG. Here, we present modelling results from the first fully coupled climate-ice sheet simulation of the LIG period (135 to $115 \mathrm{kyr} \mathrm{BP}$ ) using ice sheet models of the GrIS and AIS and a climate model of intermediate complexity. In this setup, LIG sea-level evolution and climate-ice sheet interactions can be modelled in a consistent framework. With focus on climate and ice sheet changes in Greenland and Antarc- 


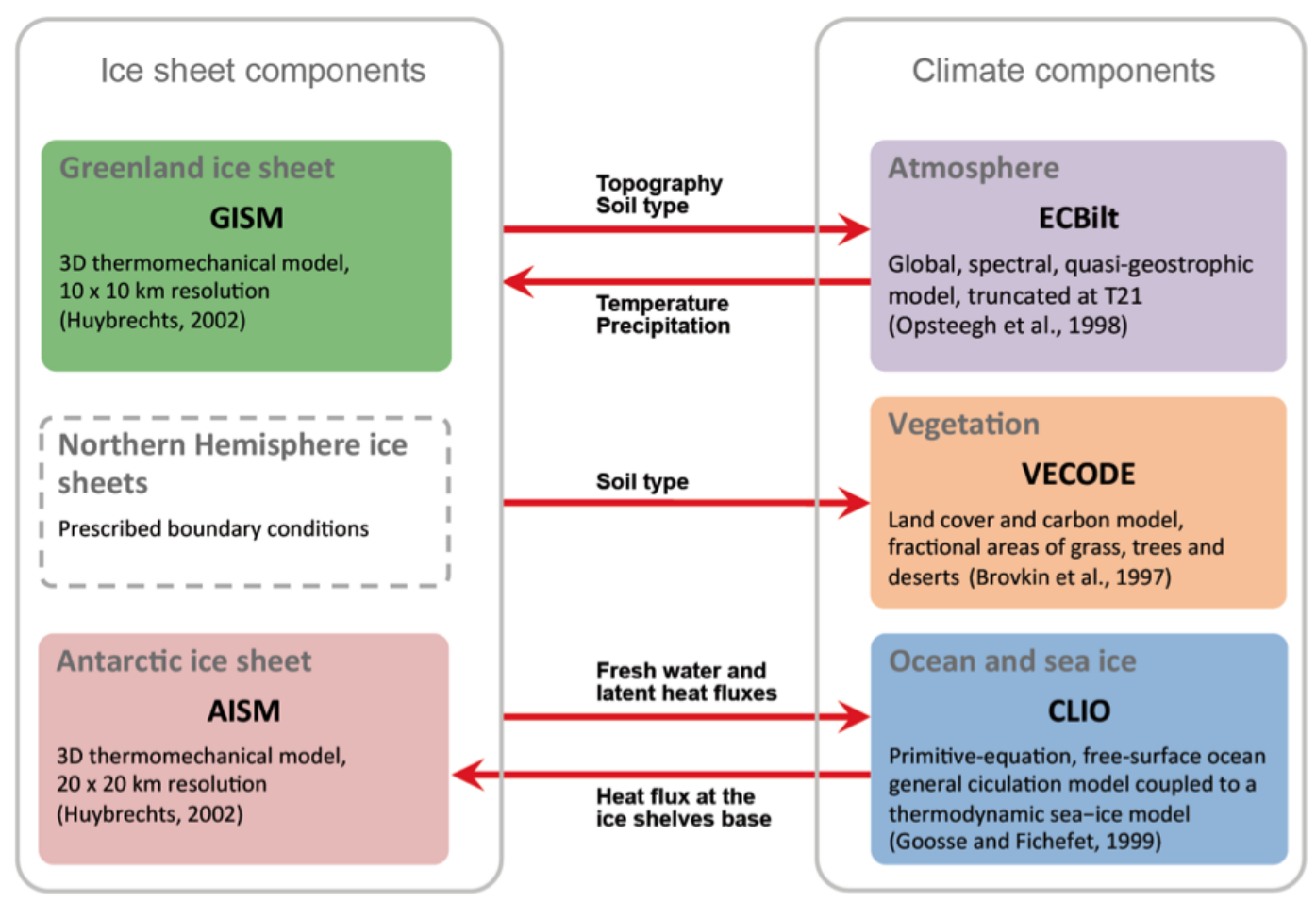

Figure 1. LOVECLIM model setup for the present study including dynamic components for the Greenland and Antarctic ice sheets and prescribed Northern Hemisphere ice sheet boundary conditions.

tica and corresponding sea-level changes, we compare results from the fully coupled model to previous climate simulations with prescribed ice sheet changes and uncoupled ice sheet experiments. In the following, we describe the model (Sect. 3) and the experimental setup (Sect. 4) and present results (Sect. 5) and conclusions (Sect. 6).

\section{Model description}

We use the Earth system model of intermediate complexity LOVECLIM version 1.3, which includes components representing the atmosphere, the ocean and sea ice, the terrestrial biosphere, and the Greenland and Antarctic ice sheets (Fig. 1). The model has been utilised in a large number of coupled climate-ice sheet studies (e.g. Driesschaert et al., 2007; Swingedouw et al., 2008; Goelzer et al., 2011, 2012). Version 1.2 is described in detail in Goosse et al. (2010). The present setup of the climate model component is identical to the model used in Loutre et al. (2014) and Goelzer et al. (2016). Whereas in the latter study the ice sheet components were prescribed and used as forcing for the climate model, in the present work, they are fully two-way coupled with information exchanged every full year. The model components for the GrIS and AIS are three-dimensional thermomechanical ice-dynamic models (Huybrechts and de Wolde, 1999), which have been utilised for long-term stand-alone ice sheet simulations in the past (Huybrechts, 2002). Their behaviour in the coupled system and detailed analysis of the ice sheet mass balance components are described in Huybrechts et al. (2011). The surface mass balance model is based on the positive-degree-day (PDD) method (Janssens and Huybrechts, 2000) and distinguishes between snow accumulation, rainfall, and meltwater runoff, all parameterised as a function of temperature. Surface melt is estimated based on two distinct PDD factors for ice and snow and may be retained and refreeze in the snow pack. Melt model parameters are unmodified compared to earlier studies (Goosse et al., 2010; Huybrechts et al., 2011) and have been extensively validated for the present day (e.g. Vernon et al., 2013).

Because of the relatively coarse resolution of the atmosphere in LOVECLIM (T21), the higher-resolution ice sheet models $(10 \times 10 \mathrm{~km}$ for Greenland and $20 \times 20 \mathrm{~km}$ for Antarctica) are forced with temperature anomalies and precipitation ratios relative to the pre-industrial reference climate. Climate anomalies are interpolated to the ice sheet grids using Lagrange polynomials and the surface mass balance-elevation feedback is accounted for natively in the PDD model on the ice sheet grid.

The ice sheet models in turn provide the climate model with changing topography, ice sheet extent (albedo), and spatially and temporally variable freshwater fluxes. The coupling procedure for these variables is unmodified compared to earlier versions of the model (Goosse et al., 2010), while 
recent model improvements for the ice-climate coupling interface are described in Appendix A.

\subsection{Pre-industrial reference model state}

A pre-industrial climate state required as a reference for the anomaly forcing mode is generated by running the climate model with fixed present-day modelled ice sheet configuration to a steady state. Standard settings for orbital parameters and greenhouse gas forcing for this experiment are applied following the PMIP3 protocol (https://pmip3.lsce.ipsl.fr/). The present-day ice sheet configurations for the GrIS and AIS are the result of prolonging the same stand-alone ice sheet experiments used to initialise the LIG ice sheet configuration described below towards the present day (Huybrechts and de Wolde, 1999; Huybrechts, 2002; Goelzer et al., 2016).

\subsection{Northern Hemisphere ice sheet forcing}

At the onset of the LIG, large Northern Hemisphere (NH) ice sheets other than on Greenland were still present and melted away over the course of several millennia. To account for these ice sheet changes and their impact on climate and ocean evolution, a reconstruction of the penultimate deglaciation of the NH is necessary for our experiments starting in $135 \mathrm{kyr}$ BP. Because there is very little geomorphological evidence for $\mathrm{NH}$ ice sheet constraints during Termination II, a reconstruction of $\mathrm{NH}$ ice sheet evolution is made by remapping the retreat after the Last Glacial Maximum according to the global ice volume reconstruction (Lisiecki and Raymo, 2005) during the onset of the LIG. The same procedure has already been used in earlier work to produce $\mathrm{NH}$ ice sheet boundary conditions for climate model simulations (Loutre et al., 2014; Goelzer et al., 2016).

\subsection{Modelled sea-level change}

The modelled sea-level evolution takes into account contributions from the prescribed $\mathrm{NH}$ ice sheets, the GrIS and AIS, and the steric contribution due to density changes in the ocean water. The only component not explicitly modelled is the contribution of glaciers and small ice caps, which have been estimated to give a maximum contribution of $0.42 \pm 0.11 \mathrm{~m}$ during the LIG (Masson-Delmotte et al., 2013) and may contain as much as 5-6 m sea-level equivalent during glacial times (CLIMAP, 1981; Clark et al., 2001).

Changes in the sea-level contribution of the GrIS can be directly related to its net mass balance (MB), composed of snow accumulation (ACC), surface meltwater runoff (RUN), basal melting (BAS), and iceberg calving flux (CAL):

$\mathrm{MB}=\mathrm{ACC}-\mathrm{RUN}-\mathrm{BAS}-\mathrm{CAL}$.

Since the GrIS model ignores the small bodies of floating ice in the north, these values are taken over the ice sheet proper only.
For the AIS, CAL is replaced by the flux across the grounding line (GRF) in the definition of the net mass balance of the grounded ice sheet $\mathrm{MB}_{\mathrm{gr}}$, which needs further corrections to estimate changes in sea level (see below):

$\mathrm{MB}_{\mathrm{gr}}=\mathrm{ACC}-\mathrm{RUN}-\mathrm{BAS}-\mathrm{GRF}$.

The net mass balance of Antarctic floating ice shelves $\mathrm{MB}_{\mathrm{fl}}$ given here for completeness includes GRF as an additional source term, but does not contribute to sea-level changes in our model:

$\mathrm{MB}_{\mathrm{fl}}=\mathrm{GRF}+\mathrm{ACC}-\mathrm{RUN}-\mathrm{BAS}-\mathrm{CAL}$.

The Antarctic contribution to global sea-level change is calculated taking into account corrections for grounded ice replacing seawater, grounded ice being replaced by seawater and seawater being replaced by isostatic bedrock movement. These effects are mainly of importance for the marine sectors of the WAIS. Note that these effects are not considered in the climate model, which operates with a fixed presentday land-sea mask. The additional correction for bedrock changes is responsible for a $\sim 3 \mathrm{~m}$ lower sea-level contribution at $135 \mathrm{kyr}$ BP compared to taking only changes in volume above floatation into account. This additional sea-level depression arises from depressed bedrock under the load of the ice in the marine sectors of the ice sheet.

For the GrIS, the same corrections are applied, where the marine extent of ice grounded below sea level is parameterised. However, the corrections imply only a $\sim 30 \mathrm{~cm}$ lower contrast to present-day sea level due to GrIS expansion at $135 \mathrm{kyr} \mathrm{BP}$ and $\sim 15 \mathrm{~cm}$ higher at $130 \mathrm{kyr} \mathrm{BP}$ compared to calculations based on the entire grounded ice volume. The change in sign arises from bedrock changes in delayed response to ice loading changes coming out of the penultimate glacial period.

The steric component of global sea level considers density changes due to local changes in temperature and salinity, but global salinity is restored as often done in ocean models to guarantee stability.

\section{Experimental setup}

\subsection{Model forcing}

All simulations are forced by time-dependent changes in greenhouse gas (GHG) concentrations and insolation running from 135 until $115 \mathrm{kyr}$ BP (Fig. 2). The radiative forcing associated with the reconstructed GHG levels is below pre-industrial values for most of this period and hardly exceeds it at $\sim 128 \mathrm{kyr}$ BP (Fig. 2b). The changes in the distribution of insolation received by the Earth are computed from the changes in the orbital configuration (Berger, 1978) and represent the governing forcing during peak LIG conditions (Fig. 2a).

In order to account for coastline changes and induced grounding-line changes, both ice sheet models are forced by 

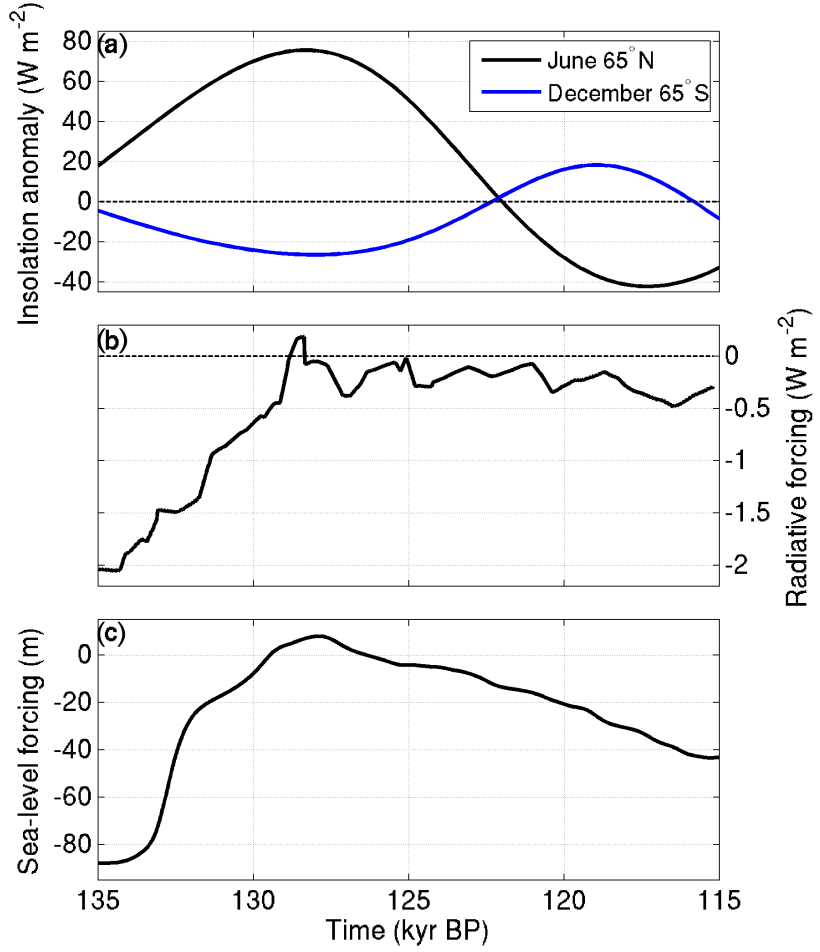

Figure 2. Prescribed model forcing. (a) Average monthly insolation anomaly at $65^{\circ} \mathrm{N}$ in June (black) and $65^{\circ} \mathrm{S}$ in December (blue) to illustrate the spatially and temporally resolved forcing (Berger, 1978), (b) combined radiative forcing anomaly of prescribed greenhouse gas concentrations relative to the present day, and (c) sealevel forcing for the ice sheet components derived from a Red Sea sea-level record (Grant et al., 2012).

Table 1. Overview of all discussed model experiments. The second column gives the scale factor $R$ for temperature anomalies over the Greenland ice sheet.

\begin{tabular}{lrl}
\hline Name & $R$ & Description \\
\hline Reference & 0.4 & Fully coupled reference simulation \\
High & 0.5 & Fully coupled simulation \\
Low & 0.3 & Fully coupled simulation \\
Forced reference & 0.4 & Forced with climate output from Reference \\
Forced high & 0.5 & Forced with climate output from Reference \\
Forced low & 0.3 & Forced with climate output from Reference \\
No sub-shelf melting & 0.4 & Suppressed Antarctic sub-shelf melting \\
\hline
\end{tabular}

changes in global sea-level stand (Fig. 2c) using a recent sea-level reconstruction based on Red Sea data (Grant et al., 2012). The chronology of these data is thought to be superior compared to sea-level proxies based on scaled benthic $\delta^{18} \mathrm{O}$ records (Grant et al., 2012; Shakun et al., 2015). In this sea-level forcing approach, local changes due to geoidal eustasy are not taken into account, which would result in loweramplitude sea-level changes close to the ice sheets, but that would not be consistent with the stand-alone spin-up of the ice sheet models.
As mentioned earlier, the ice sheet models are forced with temperature anomalies relative to the pre-industrial reference climate. To ensure a realistic simulation of the GrIS evolution, the temperature anomaly forcing from the climate model over the GrIS needs to be rescaled. In the absence of such scaling, the ice sheet almost completely melts away over the course of the LIG in disagreement with the ice core data, which suggests a large remaining ice sheet during the LIG (Dansgaard et al., 1982; NEEM community members, 2013). In the absence of firm constraints on the climate evolution over the ice sheet, the temperature scaling in the present study represents a pragmatic solution to produce a GrIS evolution reasonably in line with ice core constraints on minimum ice sheet extent during the LIG. The scaling is only applied for the GrIS, since we have not identified a physical process that would justify a similar procedure for to the AIS.

\subsection{Reference simulation and sensitivity experiments}

Our reference simulation is a fully coupled experiment with a uniform scaling of the atmospheric temperature anomaly over Greenland with a factor of $R=0.4$, which was chosen to give a good match to constraints on minimum extent of the GrIS during the LIG. Additional sensitivity experiments are listed in Table 1 and are described in the following.

Two sensitivity experiments with modified scaling $(R=0.5,0.3)$ are added to evaluate the impact on the results. The range of parameter $R$ is chosen to retain an acceptable agreement of the minimum GrIS extent during the LIG with reconstructions. In practice, the high scaling factor $(R=0.5)$ is chosen to produce the smallest minimum ice sheet extent, which still has ice at the NEEM site. The low scaling factor ( $R=0.3$ ) was adopted to produce the smallest minimum ice sheet extent, which is still covering Camp Century.

The three fully coupled experiments are complemented by additional sensitivity experiments, in which the ice sheet models are forced with (modified) climate forcing produced by the fully coupled reference run. These experiments serve to study ice sheet sensitivity in response to changes in the climate forcing and are also used to evaluate ice sheet-climate feedbacks by comparing the coupled and uncoupled system. The ice sheet evolution in the forced reference experiment (ice sheet model run offline with the recorded climate forcing of the coupled reference run) should by construction be identical to the response in the fully coupled run, and only serves as a control experiment. Two additional forced experiments have been run with modified temperature scaling for the GrIS $(R=0.5,0.3)$, which can be directly compared to the respective fully coupled experiment.

For the AIS, an experiment with suppressed sub-shelf melting has been performed to isolate the effect of ocean temperature changes on the ice volume evolution and sealevel contribution. 


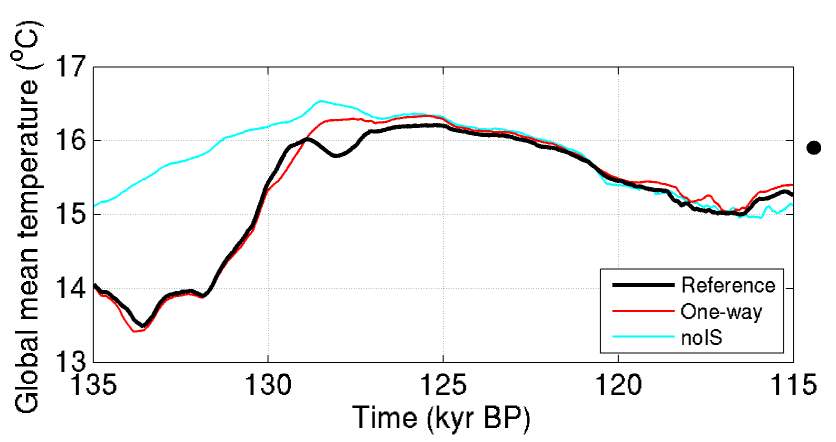

Figure 3. Global annual mean near-surface air temperature evolution of the reference run (black) compared to experiments with prescribed Greenland and Antarctic ice sheet evolution from standalone experiments (One-way, red) and no ice sheet changes at all (noIS, light blue). The filled circle on the right axis indicates the temperature for a pre-industrial control experiment of the reference model with present-day ice sheet configuration.

\subsection{Initialisation of the reference simulation}

The goal of our initialisation technique is to prepare a coupled ice sheet-climate model state for the transient simulations starting at $135 \mathrm{kyr} \mathrm{BP}$ exhibiting a minimal coupling drift. Both ice sheet models are first integrated over the preceding glacial cycles in order to carry the long-term thermal and geometric history with them (Huybrechts and de Wolde, 1999; Huybrechts, 2002; Goelzer et al., 2016). The climate model is then initialised to a steady state with ice sheet boundary conditions, greenhouse gas forcing, and orbital parameters for the time of coupling (135 kyr BP). When LOVECLIM is integrated forward in time in fully coupled mode, the climate component is already relaxed to the ice sheet boundary conditions. The mismatch between standalone ice sheet forcing and climate model forcing is incrementally adjusted in the period $135-130 \mathrm{kyr}$ BP with a linear blend between the two to minimise the effect of changing boundary conditions for the ice sheet model. A small, unavoidable coupling drift of the ice sheet component arises from a switch of spatially constant to spatially variable temperature and precipitation anomalies at the time of coupling, but this is uncritical to the results.

\section{Results}

The modelled LIG climate evolution and comparison with proxy reconstructions were presented in detail in two earlier publications (Loutre et al., 2014; Goelzer et al., 2016) for the same climate model setup. In the following, we focus on differences to those two works that arise from a different ice sheet evolution and from the incorporation of feedbacks between climate and ice sheets that are taken into account in our present, fully coupled approach. In addition, we present re-
Table 2. Peak sea-level contribution in sea-level equivalent (SLE) and timing from the Greenland ice sheet above present-day levels for three different parameter choices.

\begin{tabular}{lcr|rr}
\hline \multirow{2}{*}{ Name } & \multicolumn{2}{c|}{ Fully coupled experiments } & \multicolumn{2}{|c}{ Forced repeat experiments } \\
\cline { 2 - 5 } & $\begin{array}{r}\text { SLE } \\
(\mathrm{m})\end{array}$ & $\begin{array}{r}\text { time of peak } \\
(\mathrm{kyr} B P)\end{array}$ & $\begin{array}{r}\text { SLE } \\
(\mathrm{m})\end{array}$ & $\begin{array}{r}\text { time of peak } \\
(\mathrm{kyr} B P)\end{array}$ \\
\hline High & +2.72 & 122.8 & +2.01 & 123.6 \\
Reference & +1.42 & 123.3 & +1.42 & 123.3 \\
Low & +0.65 & 124.0 & +0.81 & 123.7 \\
\hline
\end{tabular}

sults pertaining to the ice sheet evolution and simulated sealevel changes.

\subsection{Climate evolution}

Global annual mean near-surface air temperature in the reference experiment (Fig. 3) shows a distinct increase until $129 \mathrm{kyr}$ BP in response to orbital and greenhouse gas forcing (Fig. 2) and to an even larger extent in response to changes in ice sheet boundary conditions. The peak warming reaches $0.3^{\circ} \mathrm{C}$ above the pre-industrial period at $125.5 \mathrm{kyr} \mathrm{BP}$. Thereafter, cooling sets in and continues at a much lower rate compared to the rate of warming before $129 \mathrm{kyr} B$. The importance of ice sheet changes is illustrated by comparing the reference experiment with a climate simulation (Loutre et al., 2014) forced by insolation and GHG changes only (noIS) and with a one-way coupled climate model run (Goelzer et al., 2016) forced with prescribed NH, Antarctic, and Greenland ice sheet changes (One-way). The fully coupled experiment exhibits a global mean temperature evolution during the LIG, which is very similar to One-way (Fig. 3). A much larger temperature contrast at the onset of the LIG in the reference experiment compared to noIS arises mainly from changes in surface albedo and melt water fluxes of the $\mathrm{NH}$ ice sheets, which freshen the North Atlantic and lead to a strong reduction of the Atlantic meridional overturning circulation (Loutre et al., 2014). All three simulations show only small differences in the global mean temperature evolution after $127 \mathrm{kyr}$ BP. The episode of relative cooling in the reference experiment with a local temperature minimum at $128 \mathrm{kyr} \mathrm{BP}$ is due to cooling of the Southern Ocean (SO) and sea-ice expansion in response to large Antarctic freshwater fluxes caused mainly by the retreat of the WAIS. This mechanism has already been described by Goelzer et al. (2016), but now occurs $2 \mathrm{kyr}$ later in the fully coupled experiment, due to a modified timing of the AIS retreat. The effect of including ice-climate feedbacks by means of a two-way coupling is otherwise largely limited to the close proximity of the ice sheets as discussed in the following. 

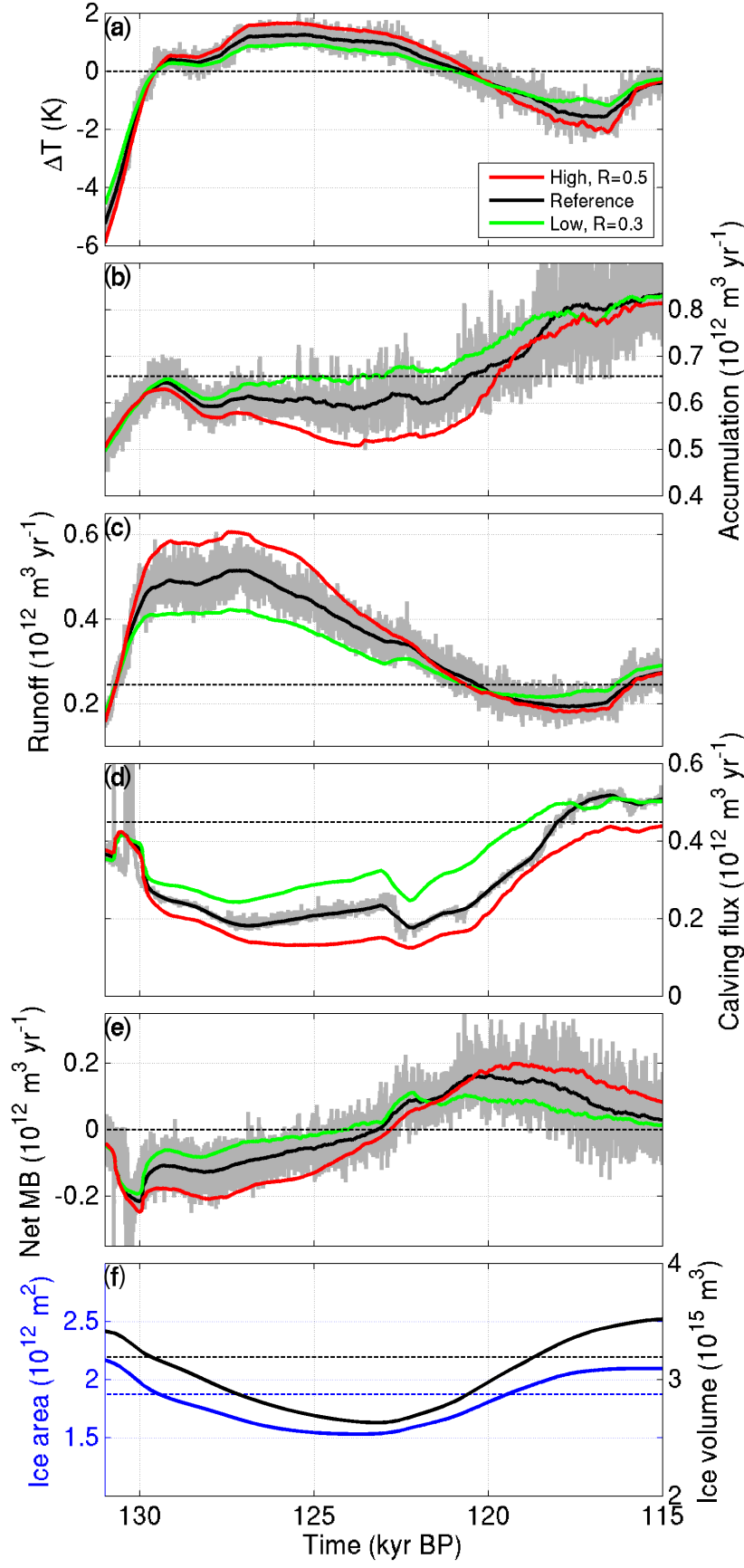

Figure 4. Greenland ice sheet forcing characteristics for the reference run (black) and with higher (red) and lower (green) temperature scaling. Climatic temperature anomaly relative to preindustrial (a). Accumulation (b) and surface meltwater runoff (c) over grounded ice. Calving flux (d), net mass balance (e), and other mass balance terms $(\mathbf{b}, \mathbf{c})$ given in water equivalent. Ice area (blue) and ice volume (black) for the reference run (f). All lines are smoothed with a 400-year running mean except for the grey lines giving the full annual time resolution for the reference run. Horizontal dashed lines give the pre-industrial reference values, except for panel $\mathbf{e}$, where it is the zero line.

\subsection{Greenland ice sheet}

The Greenland ice sheet evolution over the LIG period is largely controlled by changes in the surface mass balance dominated by surface meltwater runoff (Fig. 4c). Specifically, summer surface melt water runoff from the margins is the dominant mass loss of the GrIS after $130 \mathrm{kyr}$ BP, when the ice sheet has retreated largely on land. Due to increased air temperatures over Greenland, the mean accumulation rate (averaged over the ice-covered area) is consistently above the present-day reference level after $128 \mathrm{kyr} \mathrm{BP}$, but increases to at most $18 \%$ higher (not shown). In contrast, net accumulation over grounded ice (Fig. 4b) is strongly modulated by the retreat of the ice sheet and exhibits a marked increase towards the end of the simulation as ice sheet grows again and into regions with higher precipitation. Conversely, surface meltwater runoff over the Greenland ice sheet shows an up to 3-fold increase compared to the present day at the beginning with consistently higher-than present values between $130.5 \mathrm{kyr}$ and $120.5 \mathrm{kyr}$ BP (Fig. 4c). Temperature anomalies responsible for the increased runoff are on average above zero between $129.5 \mathrm{kyr}$ and $120.5 \mathrm{kyr} \mathrm{BP}$ and peak at $1.3^{\circ} \mathrm{C}$ (after scaling) around $125 \mathrm{kyr}$ BP (Fig. 4a). The calving flux (Fig. 4d) decreases as surface melting and runoff (Fig. 4c) increase, removing some of the ice before it can reach the coast and also as the ice sheet retreats from the coast (see Fig. 5), in line with decreasing area and volume (Fig. 4f). In the second half of the experiment, runoff decreases with decreasing temperature anomalies and the calving flux increases again with increasing ice area and volume. The net mass balance of the ice sheet (Fig. 4e) reflects the compounded effect of all components with negative values before and positive values after the time of minimum volume.

Entering the warm period, the furthest retreat of the ice sheet occurs in the south-west and north-west (Fig. 5), accompanied by an overall retreat from the coast. At the same time, the ice sheet gains in surface elevation over the central dome due to increased accumulation. By $115 \mathrm{kyr} \mathrm{BP}$, the ice sheet has regrown beyond its present-day area almost everywhere and contact with the ocean is increasing. The GrIS volume change implies a sea-level contribution peak of $1.4 \mathrm{~m}$ at $123 \mathrm{kyr} \mathrm{BP}$ (Fig. 11a). For the two sensitivity experiments (High, Low) with modified scaling $(R=0.5,0.3)$, the contribution changes to $2.7 \mathrm{~m}$ and $0.65 \mathrm{~m}$, respectively, crucially controlled by the scaling factor (Table 2).

NEEM ice core data (NEEM community members, 2013) and radiostratigraphy of the entire ice sheet (MacGregor et al., 2015) indicate that the NEEM ice core site was icecovered through the entire Eemian as is the case for our reference experiment. Elevation changes from that ice core are, however, not very well constrained, and even if they were, they would leave room for a wide range of possible retreat patterns of the northern GrIS (e.g. Born and Nisancioglu, 2012). The Camp Century ice core record contains some ice in the lowest part with a colder signature than ice dated as be- 

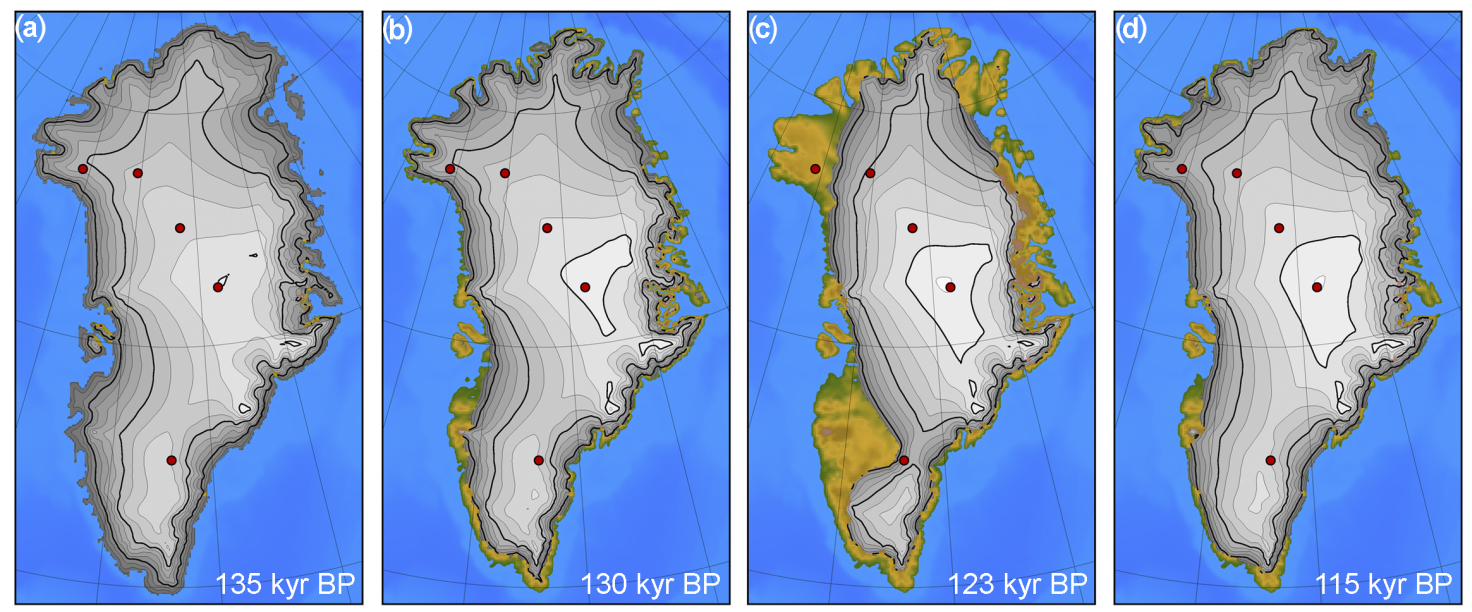

$\mathrm{km}$

0

1000

Figure 5. Greenland ice sheet geometry at $135 \mathrm{kyr} \mathrm{BP}(\mathbf{a})$, at $130 \mathrm{kyr} \mathrm{BP}(\mathbf{b})$, for the minimum ice sheet volume at $123 \mathrm{kyr}$ BP with a sea-level contribution of $1.4 \mathrm{~m} \mathrm{(c),} \mathrm{and} \mathrm{at} \mathrm{the} \mathrm{end} \mathrm{of} \mathrm{the} \mathrm{reference} \mathrm{experiment} \mathrm{at} 115 \mathrm{kyr}$ BP (d). The red dots indicate the deep ice core locations (from south to north-west: Dye-3, GRIP, NGRIP, NEEM, Camp Century).

longing to the Eemian period (Dansgaard et al., 1982). It is likely that this ice is from before the Eemian even in view of possible disturbance of the lower levels, which was shown to exist for the NEEM core site (NEEM community members, 2013). In view of this evidence, the north-western retreat of the ice sheet in our reference simulation may be too far inland, as a direct result of the largely unconstrained climatic forcing in this area. It was shown that a different climate forcing could produce a larger northern retreat still in line with the (limited) palaeo-evidence (Born and Nisancioglu, 2012). Some more thinning and retreat in the south is also possible without violating constraints on minimal ice sheet extent from Dye-3 (Dansgaard et al., 1982). LIG ice cover of the Dye-3 site is not a necessity when taking into consideration that older ice found at the base of the core could have flowed in from a higher elevation.

A comparison of modelled temperatures in north-eastern Greenland (Fig. 6) shows differences of up to $5^{\circ}$ between annual mean and summer temperatures in the reference experiment. Comparison with temperature reconstructions based on the NEEM ice core record indicates that the steep temperature increase marking the onset of the LIG occurs 2-3 kyr earlier in the model compared to the reconstructions. The amplitude of modelled summer temperatures attains levels of the central estimate, while annual mean temperatures fall in the lower uncertainty range of the reconstructions. Temperatures exceeding the central estimate are only reached in the One-way experiment, which exhibits a somewhat different retreat pattern of the GrIS due to the different climate forcing (Goelzer et al., 2016).

The strength of the ice-climate feedback on Greenland was examined by comparing additional experiments in which the coupling between ice sheet and climate is modified. Re-

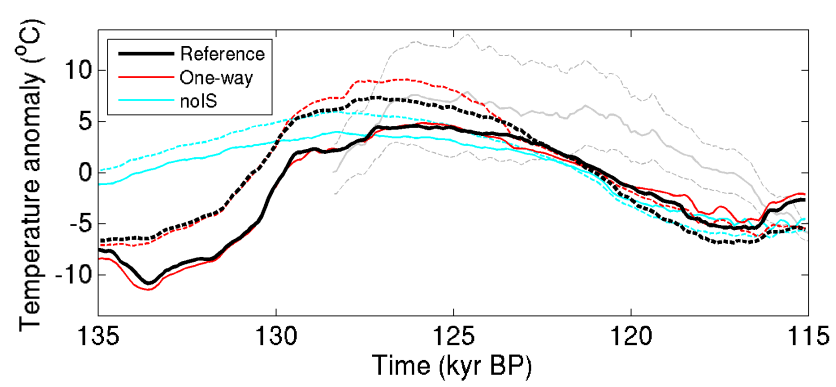

Figure 6. Comparison of modelled north-eastern Greenland annual mean (solid) and summer (June-July-August, dashed) surface temperature evolution $\left(72-83^{\circ} \mathrm{N}\right.$ and $\left.306^{\circ} 33^{\prime}-317^{\circ} 48^{\prime} \mathrm{E}\right)$ with reconstructed temperature changes (grey) at deep ice core site NEEM $\left(77^{\circ} 27^{\prime} \mathrm{N}, 308^{\circ} 56^{\prime} \mathrm{E}\right)$. The solid grey line is the central estimate and grey dashed lines give the estimated error range for NEEM (NEEM community members, 2013).

sults from the fully coupled model are compared to those from forced ice sheet runs that are driven with the climate forcing from the coupled reference model run (Table 2 and Fig. 7a). The scaling of Greenland forcing temperature is set to a magnitude of 0.3 (Forced low), 0.4 (Forced reference), and 0.5 (Forced high), respectively. When the feedback between ice sheet changes and climate is included in the coupled experiments, the warming over the margins is considerably increased (reduced) for experiment High (Low) compared to the respective forced experiments. Consequently, ice volume changes show a non-linear dependence on the temperature scaling for the fully coupled run, while they are near linear for the forced runs (Table 2 and Fig. 7a). The dominant (positive) feedback mechanism arises from how changing albedo characteristics are taken into account for 

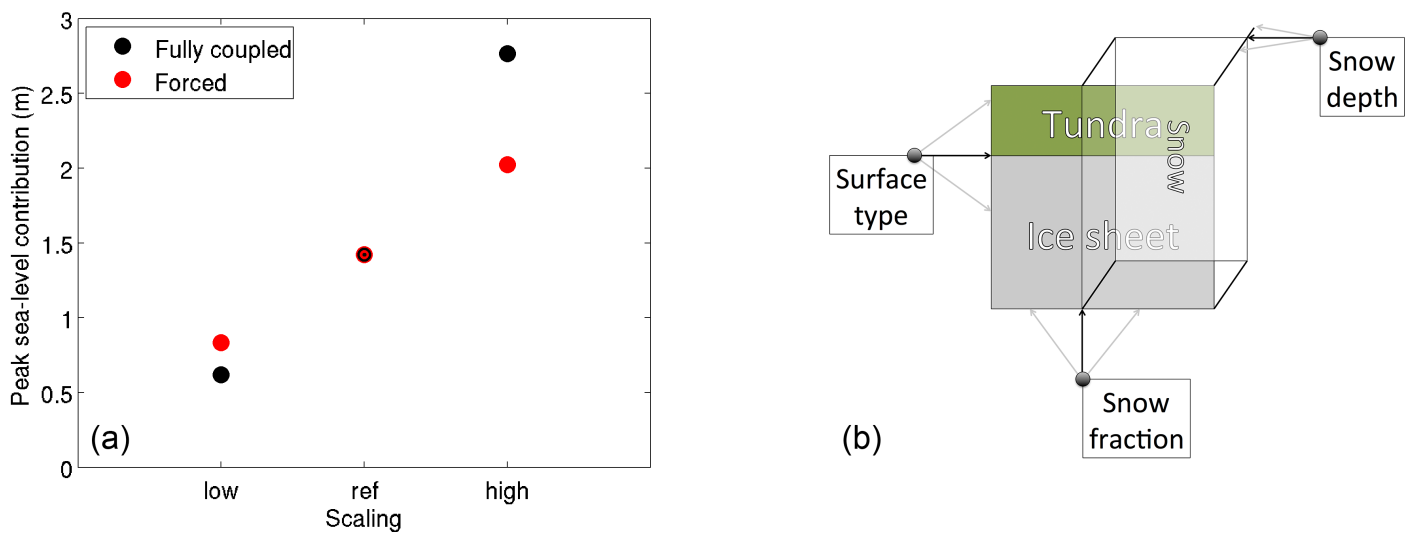

Figure 7. Scaling of sea-level contribution from the Greenland ice sheet as a function of temperature changes for the full model (black) and forced model (red) in comparison (a). Schematic of the albedo parameterisation in the land model for (partially) ice-covered areas (b), which is a function of the underlying surface type, snow fraction, and snow depth. See main text for details.

a melting ice sheet surface (Fig. 7b). The underlying surface type with different characteristic albedo values for tundra and ice sheet is determined by the relative amount of ice cover, which is modified when the area of the ice sheet is changing. On much shorter timescales, the albedo can change due to changes in snow depth and also due to changes in the snow cover fraction, which indicates how much surface area of a grid cell is covered with snow (Fig. 7b). Both snow processes lead to lower albedo and increased temperatures in places where the ice sheet starts melting at the surface. The difference in warming between forced and fully coupled experiments is, however, located over the ice sheet margins and this does not have a considerable influence on the $\mathrm{NH}$ or global temperature response. The snow albedo effects are near-instantaneous and their importance for the ice sheet response underline earlier findings that a basic albedo treatment is an essential aspect of a coupled ice-climate modelling system (e.g. Robinson and Goelzer, 2014). A comparatively smaller effect, operating on much longer timescales, arises from the retreating ice sheet margin being replaced by tundra with a lower albedo (Fig. 7b).

\subsection{Antarctic ice sheet}

The annual mean air temperature anomaly over Antarctica (averaged over grounded ice) increases at the beginning of the experiment, reaching a peak of up to $2{ }^{\circ} \mathrm{C}$ at $125 \mathrm{kyr} \mathrm{BP}$ (Fig. 8a) before cooling sets in and continues until $115 \mathrm{kyr}$ BP. The warming before the peak is around a factor of 2 faster than the cooling afterwards, with both transitions being near linear on the millennial timescale. The surface climate over the AIS appears to be largely isolated from millennial timescale perturbations occurring in the $\mathrm{SO}$ in response to changing freshwater fluxes in both hemispheres (Goelzer et al., 2016). While freshwater fluxes from the retreating AIS itself lead to sea-ice expansion and surface cool- ing in the $\mathrm{SO}$, freshwater fluxes from the decay of the $\mathrm{NH}$ ice sheets are communicated to the Southern Hemisphere (SH) by the interhemispheric see-saw effect (Goelzer et al., 2016). Pre-industrial surface temperature levels are first reached at $128 \mathrm{kyr} \mathrm{BP}$ and then again at $118 \mathrm{kyr} \mathrm{BP}$ after cooling throughout the second half of the experiment. The accumulation (over grounded ice) shows an initial increase in line with the higher temperatures until $130 \mathrm{kyr} \mathrm{BP}$ (Fig. 8b) but records a changing grounded ice sheet area further on, which mostly follows the marked retreat and later slow regrowth of the ice sheet. Relative to the pre-industrial period, the mean accumulation rate (averaged over grounded ice) increases at most $20 \%$ in annual values and up to $12 \%$ for the long-term mean (not shown). As a consequence of the surface forcing, the AIS shows a small volume gain until $130.5 \mathrm{kyr}$ BP (Fig. 8f) due to an increase in precipitation before a large-scale retreat of the grounding line sets in. The surface meltwater runoff over grounded ice equally increases with increasing temperature (Fig. 8c) but remains of negligible importance (note difference of vertical scales between panel $b$ and $c$ in Fig. 8) for the net mass balance (Fig. 8e) of the ice sheet. This is also the case for basal melting under the grounded ice sheet (not shown).

Changes in the sub-shelf melt rate play an important role for the present mass balance of the AIS and are often discussed as a potential forcing for a WAIS retreat during the LIG (e.g. Duplessy et al., 2007; Holden et al., 2010) and during the last deglaciation (Golledge et al., 2014). The average sub-shelf melt rate diagnosed for the area of the present-day observed ice shelves in our reference simulation (Fig. 8d) increases to at most $20 \%$ above the pre-industrial period with a peak in line with the air temperature maximum (Fig. 8a, d). However, ocean warming to above pre-industrial temperatures occurs already before $130 \mathrm{kyr}$ BP (not shown), more than $2 \mathrm{kyr}$ earlier compared to the air temperature signal. This is a consequence of the interhemispheric see-saw ef- 

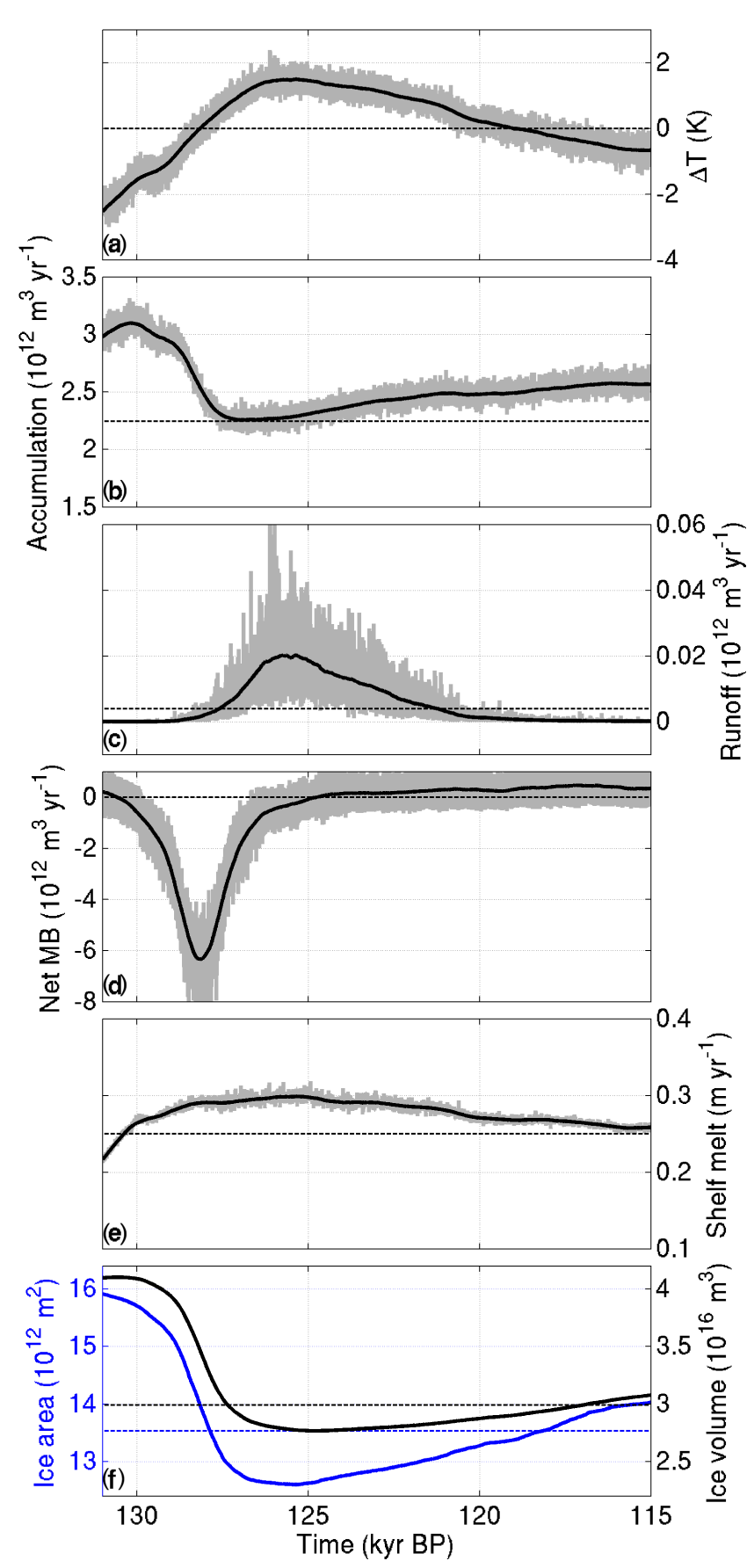

Figure 8. Antarctic ice sheet forcing and characteristics. Temperature anomaly relative to the pre-industrial period (a), accumulation (b), surface meltwater runoff (c) and net mass balance of the grounded ice sheet (d), and average sub-shelf melt rate diagnosed for the area of the present-day observed ice shelves (e). Mass balance terms (b-e) are given in water equivalent. (f) Grounded ice sheet area (blue) and volume (black). Grey lines give full annual time resolution, while black lines (and blue in f) are smoothed with a 400-year running mean. Horizontal dashed lines give the preindustrial reference values, except for (d), where it is the zero line.
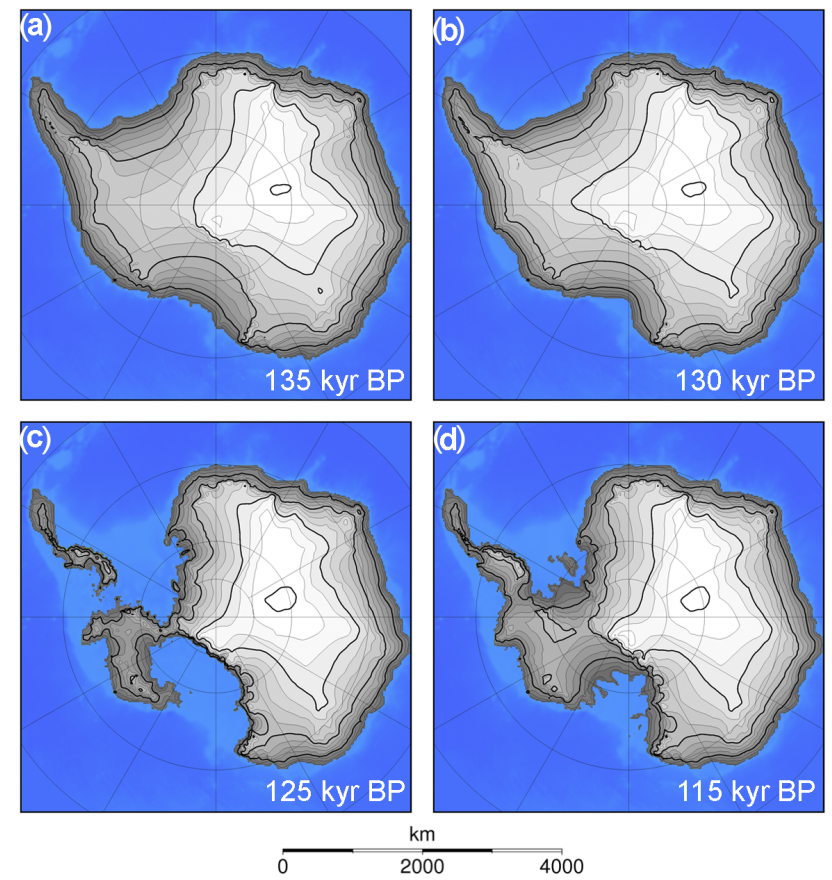

Figure 9. Antarctic grounded ice sheet geometry at $135 \mathrm{kyr}$ BP (a), $130 \mathrm{kyr} \mathrm{BP}$ (b), for the minimum ice sheet volume at $125 \mathrm{kyr} \mathrm{BP}$ with a sea-level contribution of $4.4 \mathrm{~m}$ (c), and at the end of the reference experiment at $115 \mathrm{kyr} \mathrm{BP}(\mathbf{d})$.

fect (Stocker, 1998), which explains SO warming and cooling in the North Atlantic as a consequence of reduced oceanic northward heat transport due to a weakening of the Atlantic meridional overturning circulation (Goelzer et al., 2016).

Ice sheet area and volume (Fig. 8f) decrease rapidly between 129 and $127 \mathrm{kyr}$ BP and indicate a gradual regrowth after $125 \mathrm{kyr} \mathrm{BP}$, also visible in the net mass balance (Fig. 8e). Those changes arise mainly from a retreat and re-advance of the WAIS (Fig. 9). In our model, the ice sheet retreat exhibits characteristics of an overshoot behaviour due to the interplay between ice sheet retreat and bedrock adjustment. The rebound of the bedrock, which is initially depressed under the glacial ice load, is delayed compared to the relatively rapid ice sheet retreat, giving rise to a grounding-line retreat well beyond the pre-industrial steady-state situation. These results are in line with earlier work with a stand-alone ice sheet model (Huybrechts, 2002) but also rely on a relatively large glacial-interglacial loading contrast in these particular models. The sea-level contribution above the present-day level from the AIS peaks at $125 \mathrm{kyr} \mathrm{BP}$ at $4.4 \mathrm{~m}$ (Fig. 11b).

Sensitivity experiments, in which specific forcing processes are suppressed, show that surface melting (not shown) and sub-shelf melting play a limited role for the AIS retreat in our experiments. The sea-level contribution peak in an experiment with suppressed sub-shelf melting (Fig. 11b) is about $40 \mathrm{~cm}$ lower compared to the reference experiment and remains around $1 \mathrm{~m}$ lower between $123 \mathrm{kyr} \mathrm{BP}$ and the end of 


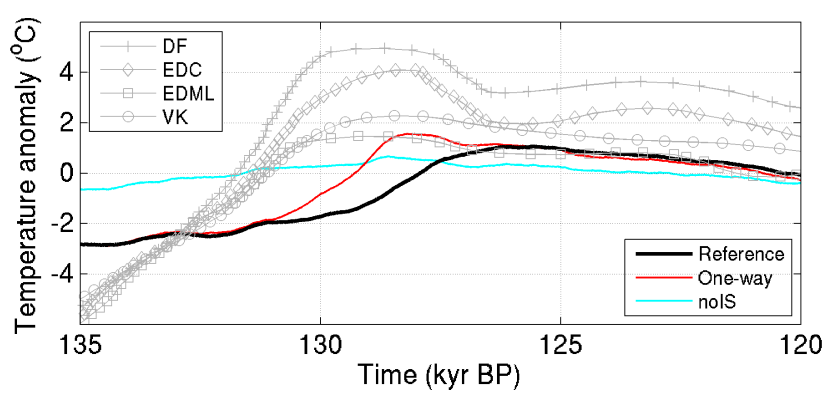

Figure 10. Comparison of modelled East Antarctic temperature evolution with reconstructed temperature changes at deep ice core sites. Modelled temperature anomalies are averaged over a region $72-90^{\circ} \mathrm{S}$ and $0-150^{\circ} \mathrm{E}$. Ice core temperature reconstructions for the sites EPICA Dronning Maud Land (EDML; $75^{\circ} 00^{\prime} \mathrm{S}, 00^{\circ} 04^{\prime} \mathrm{E}$ ), Dome Fuji (DF; $77^{\circ} 19^{\prime} \mathrm{S}, 39^{\circ} 40^{\prime} \mathrm{E}$ ), Vostok (VK; $\left.78^{\circ} 28^{\prime} \mathrm{S}, 106^{\circ} 48^{\prime} \mathrm{E}\right)$, and EPICA Dome C (EDC; $75^{\circ} 06^{\prime} \mathrm{S}$, $123^{\circ} 21^{\prime} \mathrm{E}$ ) are from Masson-Delmotte et al. (2011).

the experiment. The difference between the experiments at a given point in time arises from a lower overall sea-level contribution when sub-shelf melting is suppressed, but also from a difference in timing between both cases. The dominant forcing for the AIS retreat in our model is a combination of rising global sea level and increasing surface temperature, which leads to increasing buoyancy and reduced ice shelf viscosity, respectively. The relative timing between sea-level forcing (Fig. 2c) and temperature forcing (Fig. 8a) is therefore of critical importance for the evolution of the ice sheet at the onset of the LIG.

The limited effect of surface melting and sub-shelf melting on the sea-level contribution is ultimately due to a limited magnitude of surface temperature and ocean temperature changes. The limited Antarctic and SO temperature response has already been highlighted in earlier studies with the same climate component (Loutre et al., 2014; Goelzer et al., 2016) and is confirmed here with a fully coupled model. The feedback mechanism suggested by Golledge et al. (2014) for Termination I, which draws additional heat for sub-shelf melting from freshwater-induced SO stratification and sea-ice expansion is also active in our experiment, but too short-lived and of too little amplitude to lead to substantially increased melt rates. Our limited AIS response to climatic forcing is also in line with other modelling results for the LIG period (Pollard et al., 2015), albeit with a different forcing strategy, where substantial retreat of marine-based sectors of the EAIS can only be achieved by including special treatment of calving fronts and shelf melting, which was not included here.

As mentioned earlier, direct constraints of the AIS configuration during the LIG are still lacking. Goelzer et al. (2016) suggested that the timing of the main glacial-interglacial retreat of the AIS could be constrained by a freshwaterinduced oceanic cold event recorded in ocean sediment cores (Bianchi and Gersonde et al., 2002). The main re-

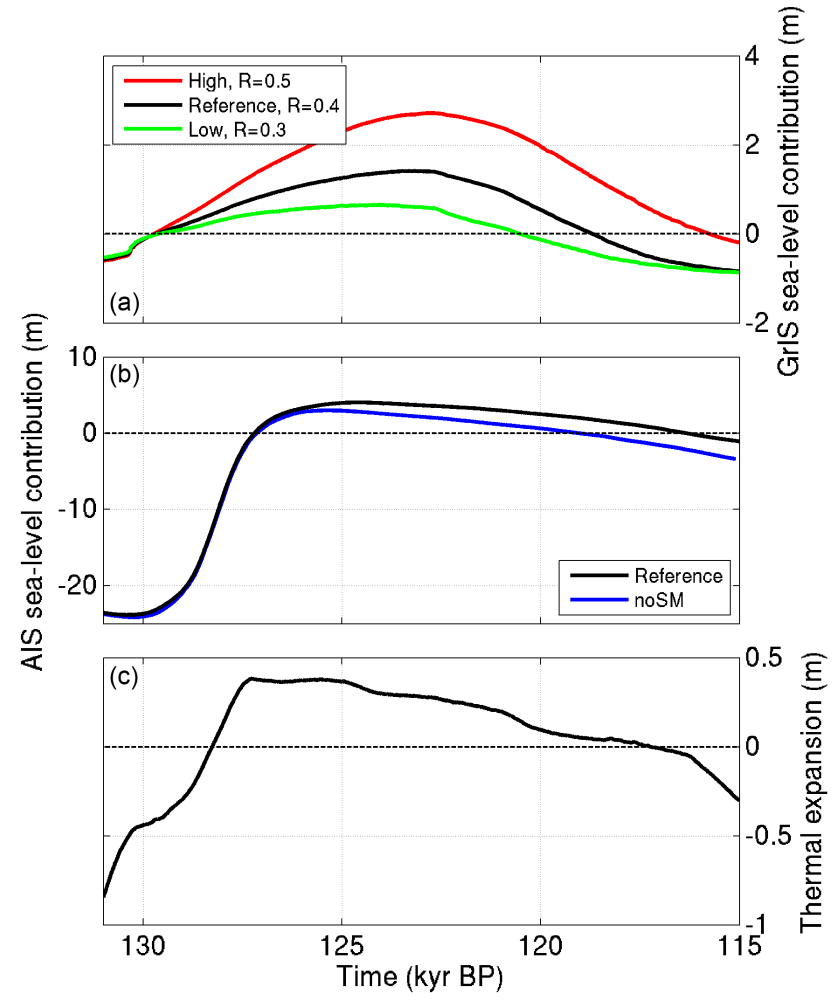

Figure 11. Sea-level contribution from the Greenland ice sheet for the reference run (black) and two sensitivity experiments with higher (red) and lower (green) temperature scaling (a). Sea-level contribution from the Antarctic ice sheet from the reference run (black) and from a sensitivity experiment without sub-shelf melting (blue) (b). Sea-level contribution from oceanic thermal expansion from the reference run (c).

treat in their one-way coupled climate model run happened $\sim 129.5 \mathrm{kyr}$ BP, a timing predating the time of retreat in the fully coupled model by $\sim 2 \mathrm{kyr}$ due to the difference in atmospheric and oceanic forcing. This lag is also visible in modelled temperature changes over the East Antarctic ice sheet (EAIS) that have been compared to temperature reconstructions for four ice core locations (Fig. 10). One-way and Reference show a larger temperature contrast, better in line with the ice core data, compared to the experiment with a fixed ice sheet (noIS). However, the timing of warming was better matched in One-way with an earlier ice sheet retreat.

It is noteworthy in this context that the prescribed sealevel forcing imposes an important control on the timing of the Antarctic retreat and is a source of large uncertainty. We have only used the central estimate of the Grant et al. (2012) sea-level reconstruction, but propagated dating uncertainties could accommodate a shift of the forcing by up to $1 \mathrm{kyr}$ either way. Previous experiments (not shown) have indicated that the main retreat appears another $2 \mathrm{kyr}$ later when a sealevel forcing based on a benthic $\delta^{18} \mathrm{O}$ record (Lisiecki and 


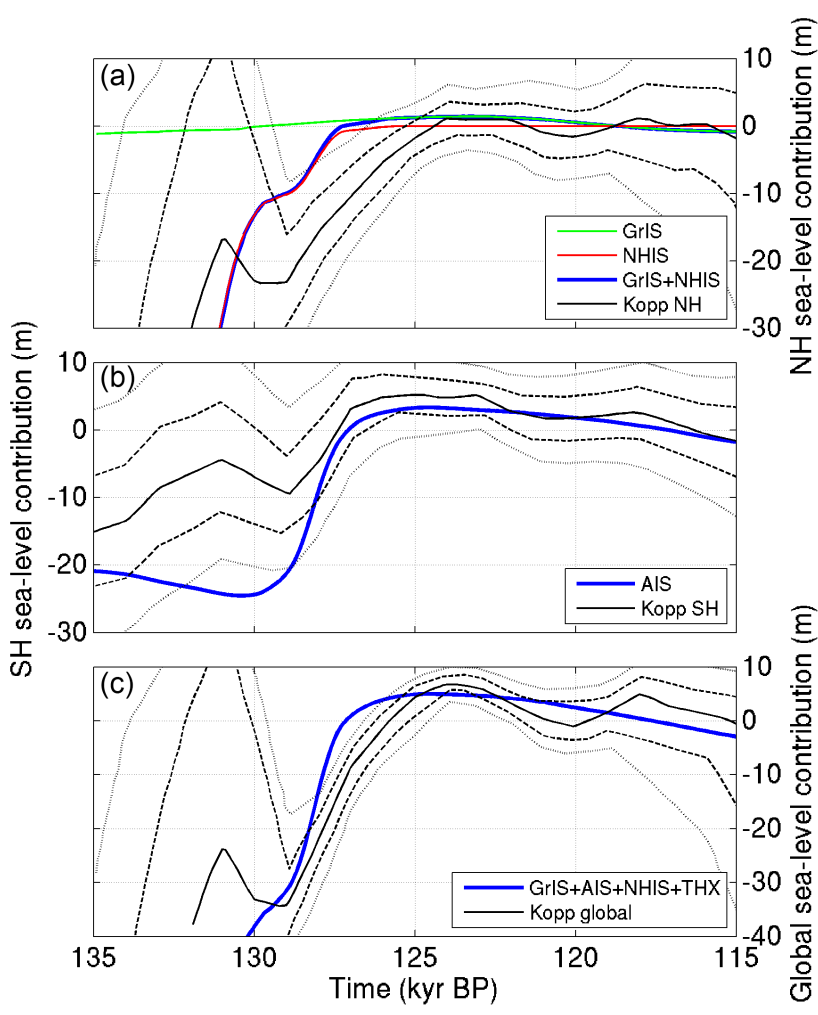

Figure 12. Modelled sea-level contributions from this study (colour lines) compared to probabilistic sea-level reconstructions (black lines) from Kopp et al. (2009) for the NH (a), the SH (b), and globally (c). For the reconstructions, solid lines correspond to the median projection, dashed lines to the 16 th and 84 th percentiles, and dotted lines to the 2.5 th and 97.5 th percentiles.

Raymo, 2005) is used instead of the sea-level reconstruction of Grant et al. (2012).

\subsection{Thermal expansion of the ocean}

The steric sea-level component due to ocean thermal expansion (Fig. 11c) is largely following the global temperature evolution (Fig. 3) but is also strongly modified by changes in ice sheet freshwater input. Ocean expansion is rapid during peak input of freshwater and stagnant during episodes of decreasing freshwater input. This is because the net ocean heat uptake is large when freshwater input peaks, which happens in three main episodes in our experiment. Two episodes of freshwater input from the $\mathrm{NH}$ centred at 133.6 and $131.4 \mathrm{kyr} \mathrm{BP}$ are followed by an episode of combined input from the $\mathrm{NH}$ and the AIS centred at $128.2 \mathrm{kyr} \mathrm{BP}$ (not shown). The anomalous freshwater input leads to stratification of the surface ocean, sea-ice expansion and reduction in the air-sea heat exchange, effectively limiting the ocean heat loss to the atmosphere. This implies that global sealevel rise due to ice sheet melting is (weakly and temporarily) amplified by the freshwater impact on ocean thermal expan- sion. We simulate a peak sea-level contribution from thermal expansion of $0.35 \mathrm{~m}$ at $125.4 \mathrm{kyr} \mathrm{BP}$, which forms part of a plateau of high contribution between 127.3 and $124.9 \mathrm{kyr}$ BP (Fig. 11c). The amplitude is within the range of current estimates of $0.4 \pm 0.3 \mathrm{~m}$ (McKay et al., 2011; Masson-Delmotte et al., 2013).

\subsection{Global sea-level change}

Combining contributions from GrIS, AIS, and thermal expansion, we find that global sea level peaks at $\sim 5.3 \mathrm{~m}$ at $124.5 \mathrm{kyr}$ BP (Fig. 12c) with a slow decrease thereafter as first the AIS and 2 kyr later the GrIS start to regrow. For the AIS the model indicates a clear asymmetry between relatively fast retreat and much slower regrowth (Fig. 12b).

Modelled GrIS and AIS sea-level contributions together with prescribed NH sea level are within the $67 \%$ confidence interval of probabilistic sea-level reconstructions (Kopp et al., 2009) for the period $\sim 125-115 \mathrm{kyr}$ BP (Fig. 12). The last $20 \mathrm{~m}$ rise in sea-level contributions from the NH (including Greenland) is steeper and occurs 1-2 kyr earlier in our model compared to what the reconstructions suggest, which is consequently also the case for the rise in global sea level at the onset of the LIG. The Antarctic retreat in our model is more rapid compared to the reconstruction and does not show the regrowth $\sim 131-129$ kyr BP suggested by the data from Kopp et al. (2009). The modelled ice sheet evolution in our reference run reproduces well the global average sealevel contribution 125-115 kyr BP based on the best estimate of Kopp et al. (2009) when taking into account the modelled steric contribution $(0.35 \mathrm{~m})$ and assuming a maximum possible contribution $(0.42 \pm 0.11 \mathrm{~m})$ of glaciers and small ice caps (Masson-Delmotte et al., 2013). The multi-peak structure of global sea-level contributions during the LIG suggested by the median reconstructions (Kopp et al., 2009, 2013) is not reproduced with our model (Fig. 12c), mainly owing to the lack of such variation in the climate forcing and to the long response times of the ice sheets during regrowth to changing climatic boundary conditions.

\section{Discussion}

\subsection{Global sea-level change}

While the median projections in Kopp et al. (2009) visually suggest a double-peak structure in the global sea-level evolution during the LIG, our results show that the uncertainty range is wide enough to accommodate a global sealevel trajectory based on physical models without intermediate low stand. The simulated climate forcing in our case does not favour the presence of such variability, which admittedly could be due to missing processes or feedbacks in our modelling. Nevertheless, based on our own modelling results and the Kopp et al. (2009) reconstruction, we are not convinced that reproducing a double-peak structure is a given necessity. 


\subsection{Greenland ice sheet evolution}

The temperature anomaly over central Greenland in the coupled model shows a flat maximum around $127 \mathrm{kyr} \mathrm{BP}$ (Fig. 4a), similar to the global temperature evolution, but $2 \mathrm{kyr}$ earlier compared to the NEEM reconstruction (NEEM community members, 2013). If assuming present-day configuration and spatially constant warming, ice mass loss from the GrIS could be expected to occur approximately as long as the temperature anomaly remains above zero, which is the case until $\sim 122 \mathrm{kyr} \mathrm{BP}$ in our reference model and until $\sim 119 \mathrm{kyr} B P$ in the NEEM reconstruction. With a lower surface elevation, the time the ice sheet starts to gain mass again would be further delayed. Even with considerable uncertainty due to uncertain spatial pattern of the warming, which modifies this simple reasoning, it is clear that the peak sea-level contribution from the GrIS has to occur late during the LIG. This argument is confirmed by our model results and in line with conclusions recently drawn by Yau et al. (2016) based on data from another Greenland ice core and modelling. Based on the same argument, there is no evidence in the reconstructed NEEM temperature evolution suggesting a regrowth or substantial pause of melting of the GrIS any time during the LIG.

The need for scaling the temperature forcing to produce a realistic GrIS evolution would equally apply if our ice sheet model were forced directly with the temperature reconstructed from the NEEM ice core record (NEEM community members, 2013). It appears that practically any ice sheet model (with melt parameters tuned for the present day) would project a near-complete GrIS meltdown if the amplitude and duration of warming suggested by the NEEM reconstructions were to apply for the entire ice sheet. This problem would be further amplified if insolation changes were explicitly taken into account in the melt model (van de Berg et al., 2011; Robinson and Goelzer, 2014). We refer to this mismatch between reconstructed temperatures and assumed minimum ice sheet extent as the "NEEM paradox" (see also Landais et al., 2016). Several attempts to solve this paradox have been made by suggesting possible biases in the interpretation of the relationship between isotope ratio and temperature, which may not be assumed temporally and spatially constant (e.g. Merz et al., 2014; Sjolte et al., 2014; SteenLarsen et al., 2014; Masson-Delmotte et al., 2015) or may be affected by changes in the precipitation regime (van de Berg et al., 2013) and sea ice conditions (Merz et al., 2016; Pedersen et al., 2016). From a modelling point of view, the decisive question is over what spatial extent and when during the year the temperature reconstruction (and possible future reinterpretations) for the NEEM site should be assumed. A central Greenland warming of large magnitude could only be reconciled with the given geometric constraints if a (much) lower warming was present over the margins and during the summer, which is where and when the majority of the mass loss due to surface melting is taking place.

\subsection{Antarctic ice sheet evolution}

The main forcing for WAIS retreat during Termination II and the LIG was found to be global sea-level rise from melting of the $\mathrm{NH}$ ice sheets, and to a lesser extent surface warming causing a gradual thinning of the ice shelves as the ice softened, contributing to an additional grounding-line retreat as there is less buttressing and increased thinning at the grounding line. These processes also played during Termination I and into the Holocene in simulations with the same ice sheet model (Huybrechts, 2002), but did not produce an overshoot in the sense that the WAIS retreated further inland from its present-day extent. The difference in behaviour between the LIG and the Holocene is mainly the speed of sea-level rise, which was slower during Termination I, and the fact that the global sea-level stand itself did not overshoot the presentday level during the Holocene, giving a less strong forcing. Of particular importance to generate overshoot behaviour is the speed of sea-level rise relative to the speed of bedrock rebound as both control the water depth at the grounding line and hence grounding-line migration because of the criterion for floatation (hydrostatic equilibrium). If the sea-level rise is fast compared to the bedrock uplift, grounding-line retreat will be enhanced, as was the case during Termination II in our model experiments. In that case, the grounding line is able to retreat to a more inland position until the lagged bedrock rebound halts and reverses the process. If, however, the bedrock rebound after ice unloading is fast compared to the sea-level rise, this will tend to dampen grounding-line retreat, as shown in the sensitivity experiments discussed in Huybrechts (2002).

Ice shelf viscosity changes also played a role during Termination II and the LIG but were not found to be the dominant forcing. The response time of viscosity changes in the ice shelves is governed by vertical heat transport, having a typical characteristic timescale of 500 years with respect to surface temperature (Huybrechts and de Wolde, 1999). The mechanism can only be effective over longer timescales and for a limited warming such as occurred during the LIG as otherwise the ice shelves would largely disintegrate from both surface and basal melting. In future warming scenarios, the effect of shelf viscosity changes is therefore usually too slow compared to the anticipated direct effect of increased surface and basal melting rates. For instance, in the future warming scenarios performed with LOVECLIM under $4 \times \mathrm{CO}_{2}$ conditions (Huybrechts et al., 2011), shelf melt rates increased 5-fold, and the ice shelves were largely gone before they had a chance to warm substantially. The implication is that analogies between these different time periods should be reserved on account of different processes playing at different timescales. 


\subsection{Comparison with other work}

An earlier attempt to model the coupled climate-ice sheet evolution for the Greenland ice sheet over the LIG period (Helsen et al., 2013) applied an asynchronous coupling strategy to cope with the computational challenge of such long simulations. While it can be assumed that their highresolution regional climate model provides a more accurate climate forcing compared to our approach, we still lack substantial climate and ice sheet reconstructions for the LIG period to effectively validate model simulations. This applies to the simulated climate as well as to the resulting ice sheet geometries, limiting attempts to constrain the GrIS sea-level contribution to arrive at relatively large and overlapping uncertainty ranges (e.g. Robinson et al., 2011; Stone et al., 2013; Helsen et al., 2013). Incidentally, our range of modelled GrIS sea-level contribution is in very close agreement with recent results from a large ensemble study of the LIG sea-level contribution constrained against present-day simulations and elevation changes at the NEEM ice core site (Calov et al., 2015). Despite a possible degree of coincidence in this particular case, the overlap between results reached by largely different methods is indicative of the lack of better constraining data needed to arrive at much narrower uncertainty ranges.

\subsection{Model limitations}

Simulating the fully coupled ice sheet-climate system for the entire duration of the LIG as presented here is an important step forward for a better understanding of the Earth system during this period. However, our attempt deserves a critical discussion of the limitations of the model setup.

A so far unavoidable side effect to running a fully coupled model for several thousands of years is the limited horizontal resolution of the atmospheric model. The katabatic wind effect discussed by Merz et al. (2014) and other small-scale circulation patterns are therefore likely underrepresented. A quantification of how much the strength of ice sheet-climate feedbacks depends on spatial resolution of the climate model would be an interesting study, but it is not something we could add to with our model setup.

The applied PDD scheme has been extensively validated with results of more complex regional climate models for simulations of the recent past (e.g. Vernon et al., 2013), but several studies point to limitations of this type of melt model when applied for periods in the past with a different orbital configuration (e.g. van de Berg et. al., 2011; Robinson and Goelzer, 2014). Their results indicate that the stronger northern summer insolation during the LIG should result in additional surface melt on the Greenland ice sheet compared to simulations based on temperature changes alone. We note that this suggests an underestimation of LIG melt with the PDD model and increased melt if it was corrected for. Thus, including an additional melt contribution due to insolation would further increase the contrast of the NEEM paradox in our simulation. Our modelling therefore provides no arguments to support the contention that the limited LIG warming implied over Greenland would be indicative of an overly sensitive ice sheet and mass balance model.

Instead, the applied scaling of the temperature anomaly forcing for the GrIS is a necessity to keep the ice sheet from losing too much mass during the warm period and to maintain ice sheet retreat to within limits of reconstructions. Clearly, this implies a limited predictive capability of our model, which is now forced to comply with the given constraints on minimum ice extent during the LIG. However, the Antarctic simulation would not be strongly affected by changes in the melt model due to the limited role of surface melting for the evolution of the AIS during the LIG.

The see-saw effect evoked by NH freshwater forcing leads to millennial timescale temperature variations in the SO, but the surface climate over the AIS is hardly affected in our simulations. Despite some improvement when ice sheet changes are included, the limited Antarctic temperature response appears to be a general feature of the LOVECLIM model (e.g. Menviel et al., 2015), which fails to reproduce a several degree warming during the LIG reconstructed at deep ice core locations. We suspect that the limited resolution of the atmospheric model contributes to this shortcoming, but we have not been able to quantify that.

\subsection{Possible improvements}

Uncertainty in the age model of the Grant et al. (2012) sealevel reconstruction could in principle be used to force the AIS to an earlier retreat, better in line with the Kopp et al. (2009) reconstructions. We have not attempted that since other uncertainties, in particular in the climate forcing, are large and do not warrant to attempt a precise chronology. Earlier experiments (not shown) indicate, however, that using a benthic $\delta^{18} \mathrm{O}$ stack (Lisiecki and Raymo, 2005) would lead to an even later retreat of the AIS and thus increase the mismatch with the Kopp et al. (2009) reconstruction. Ultimately, it would be desirable to apply a consistent sea-level forcing, based on physical models (e.g. de Boer et al., 2014). However, this would require a prognostic model of $\mathrm{NH}$ ice sheet evolution (e.g. Zweck and Huybrechts, 2005) and a general solution of the sea-level equation, which would considerably increase complexity and required resources.

Targeting model limitations described in the previous subsection hinges to a large extent on improving the atmospheric component of the climate model, which equally goes hand in hand with an increase in computational resources needed. Given the large remaining uncertainties in the climate forcing during the LIG and a limited impact of an improved physical approximation for ice flow applied to future projections (Fürst et al., 2013), we consider improving the representation of ice sheet dynamics to be of secondary importance. However, fully physical treatment of the surface mass balance 
solution in a coupled climate-ice sheet model framework, as currently targeted by several groups (e.g. Nowicki et al., 2016), appears like a promising development that may eventually be applied for palaeo-applications such as the transient LIG simulations of interest in the present paper.

\section{Conclusions}

We have presented the first coupled transient simulation of the entire LIG period with interactive Greenland and Antarctic ice sheet components. In our results, both ice sheets contribute to the sea-level high stand during the Last Interglacial, but they are subject to different forcing and response mechanisms. While the GrIS is mainly controlled by changes in surface melt water runoff, the AIS is only weakly affected by surface and sub-shelf melting. Instead, grounding-line retreat of the AIS is forced by changes in sea-level stand and, to a lesser extent, surface warming, which lowers the ice shelf viscosity. The peak GrIS contribution in our reference experiment is $1.4 \mathrm{~m}$. However, this result is strongly controlled by the need to scale the climate forcing to match existing ice core constraints on minimal ice sheet extent. This shortcoming in our modelling reflects the NEEM paradox, that strong warming over the ice sheet coincides with limited mass loss from the GrIS, indicative of a fundamental missing link in our understanding of the LIG ice sheet and climate evolution. The Antarctic contribution is $4.4 \mathrm{~m}$, predominantly sourced from WAIS retreat. The modelled steric contribution is $0.35 \mathrm{~m}$, in line with other modelling studies. Taken together, the modelled global sea-level evolution is consistent with reconstructions of the sea-level high stand during the LIG, but no evidence is found for sea-level variations on a millennial to multi-millennial timescale that could explain a multi-peak time evolution. The treatment of albedo changes at the atmosphere-ice sheet interface plays an important role for the GrIS and constitute a critical element when accounting for ice sheet-climate feedbacks in our fully coupled approach. Large uncertainties in the projected sea-level changes remain due to a lack of comprehensive knowledge about the climate forcing at the time and a lack of constraints on LIG ice sheet extent, which are limited for Greenland and virtually absent for Antarctica.

\section{Data availability}

The LOVECLIM version 1.3 model code can be downloaded from http://www.elic.ucl.ac.be/modx/elic/index.php?id=289. 


\section{Appendix A: Ice-climate coupling improvements}

Compared to earlier versions of the model (Goosse et al., 2010), recent model improvements for the coupling interface between climate and ice sheets have been included for the present study. Ocean temperatures surrounding the AIS are now used directly to parameterise spatially explicit sub-iceshelf melt rates, defining the flux boundary condition at the lower surface of the AIS in contact with the ocean. The subshelf basal melt rate $M_{\text {shelf }}$ is parameterised as a function of local mid-depth (485-700 m) ocean-water temperature $T_{\mathrm{oc}}$ above the freezing point $T_{\mathrm{f}}$ (Beckmann and Goosse, 2003):

$M_{\text {shelf }}=\rho_{w} c_{p} \gamma_{T} F_{\text {melt }}\left(T_{\mathrm{oc}}-T_{\mathrm{f}}\right) / L \rho_{i}$,

where $\rho=910$ and $\rho=1028 \mathrm{~kg} \mathrm{~m}^{-3}$ are ice and seawater densities, $c_{p}=3974 \mathrm{~J} \mathrm{~kg}^{-1}{ }^{\circ} \mathrm{C}^{-1}$ is the specific heat capacity of ocean water, $\gamma_{T}=10^{-4}$ is the thermal exchange velocity, and $L=3.35 \times 10^{5} \mathrm{~J} \mathrm{~kg}^{-1}$ is the latent heat of fusion. The local freezing point is given (Beckmann and Goosse, 2003) as

$T_{f}=0.0939-0.057 \cdot S_{0}+7.64 \times 10^{-4} z_{b}$,

where the mean value of ocean salinity, $S_{0}$, is 35 psu and $z_{b}$ is the bottom of the ice shelf below sea level.

A distinction is made between protected ice shelves (Ross and Filchner-Ronne) with a melt factor of $F_{\text {melt }}=1.6 \times 10^{-3} \mathrm{~m} \mathrm{~s}^{-1}$ and all other ice shelves with a melt factor of $F_{\text {melt }}=7.4 \times 10^{-3} \mathrm{~m} \mathrm{~s}^{-1}$. The parameters are chosen to reproduce observed average melt rates (Depoorter et al., 2013) under the Ross, Filchner-Ronne, and Amery ice shelves for the pre-industrial LOVECLIM ocean temperature and Bedmap2 (Fretwell et al., 2013) shelf geometry. For ice shelves located inland from the fixed land-sea mask of the ocean model, mid-depth ocean temperature from the nearest deep-ocean grid point in the same embayment is used for the parameterisation.
In addition, surface melting of the Antarctic ice shelves has been taken into account, compared to earlier model versions where all surface meltwater was assumed to refreeze at the end of summer. The surface mass balance of ice sheet and ice shelf are now treated consistently with the same positive-degree-day model including capillary water and refreezing terms. The same melting schemes for basal and surface melt have been used for the AIS model version that participated in the PlioMIP intercomparison exercise of de Boer et al. (2015).

The atmospheric interface for the GrIS was redesigned to enable ice sheet regrowth from a (semi-)deglaciated state given favourable conditions. This is accomplished by calculating surface temperatures independently for different surface types (ocean, ice sheet, tundra), which most importantly prevents tundra warming from affecting proximal ice sheet margins. At the same time, the full range of atmospheric forcing is taken into account by allowing the ice sheet forcing temperature to exceed the melting point at the surface. This provides an in principle unbounded temperature anomaly forcing for increasing atmospheric heat content for the positive-degree-day melt scheme. 
Acknowledgements. We acknowledge support through the Belgian Federal Science Policy Office within its Research Programme on Science for a Sustainable Development under contract SD/CS/06A (iCLIPS). Computational resources were provided by the supercomputing facilities of the Université catholique de Louvain (CISM/UCL) and the Consortium des Equipements de Calcul Intensif en Fédération Wallonie Bruxelles (CECI) funded by the Fond de la Recherche Scientifique de Belgique (FRS-FNRS). We thank all four reviewers and the editor for constructive comments and their follow-up of the manuscript.

Edited by: D.-D. Rousseau

Reviewed by: A. Ganopolski, EW Wolff, and two anonymous referees

\section{References}

Bamber, J. L., Riva, R. E. M., Vermeersen, B. L. A., and LeBrocq, A. M.: Reassessment of the Potential Sea-Level Rise from a Collapse of the West Antarctic Ice Sheet, Science, 324, 901-903, doi:10.1126/science.1169335, 2009.

Beckmann, A. and Goosse, H.: A parameterization of ice shelfocean interaction for climate models, Ocean Modell., 5, 157170, doi:10.1016/S1463-5003(02)00019-7, 2003.

Berger, A.: Long-term variations of daily insolation and Quaternary climatic changes, J. Atmos. Sci., 35, 2362-2367, 1978.

Bianchi, C. and Gersonde, R.: The Southern Ocean surface between Marine Isotope Stages 6 and 5d: Shape and timing of climate changes, Palaeogeogr. Palaeocl., 187, 151-177, doi:10.1016/S0031-0182(02)00516-3, 2002.

Born, A. and Nisancioglu, K. H.: Melting of Northern Greenland during the last interglaciation, The Cryosphere, 6, 1239-1250, doi:10.5194/tc-6-1239-2012, 2012.

Brovkin, V., Ganopolski, A., and Svirezhev, Y.: A continuous climate-vegetation classification for use in climate-biosphere studies, Ecol. Model., 101, 251-261, doi:10.1016/S03043800(97)00049-5, 1997.

Calov, R., Robinson, A., Perrette, M., and Ganopolski, A.: Simulating the Greenland ice sheet under present-day and palaeo constraints including a new discharge parameterization, The Cryosphere, 9, 179-196, doi:10.5194/tc-9-179-2015, 2015.

Capron, E., Govin, A., Stone, E. J., Masson-Delmotte, V., Mulitza, S., Otto-Bliesner, B., Rasmussen, T. L., Sime, L. C., Waelbroeck, C., and Wolff, E. W.: Temporal and spatial structure of multi-millennial temperature changes at high latitudes during the Last Interglacial, Quaternary Sci. Rev., 103, 116-133, doi:10.1016/j.quascirev.2014.08.018, 2014.

Clark, P., Marshall, S., Clarke, G., Hostetler, S., Licciardi, J., and Teller, J.: Freshwater forcing of abrupt climate change during the last glaciation, Science, 293, 283-287, doi:10.1126/science.1062517, 2001.

CLIMAP project members: Seasonal reconstruction of the earth's surface at the last glacial maximum, Geol. Soc. Am. Map Chart Ser., MC-36, 1981.

Colville, E. J., Carlson, A. E., Beard, B. L., Hatfield, R. G., Stoner, J. S., Reyes, A. V., and Ullman, D. J.: Sr-Nd-Pb Isotope Evidence for Ice-Sheet Presence on Southern Greenland During the Last Interglacial, Science, 333, 620-623, doi:10.1126/science.1204673, 2011.
Dansgaard, W., Clausen, H. B., Gundestrup, N., Hammer, C. U., Johnsen, S. F., Kristinsdottir, P. M., and Reeh, N.: A New Greenland Deep Ice Core, Science, 218, 1273-1277, doi:10.1126/science.218.4579.1273, 1982.

de Boer, B., van de Wal, R. S. W., Lourens, L. J., Bintanja, R., and Reerink, T. J.: A continuous simulation of global ice volume over the past 1 million years with 3-D ice-sheet models, Clim. Dynam., 41, 1365-1384, doi:10.1007/s00382-012-1562-2, 2013.

de Boer, B., Stocchi, P., and van de Wal, R. S. W.: A fully coupled 3-D ice-sheet-sea-level model: algorithm and applications, Geosci. Model Dev., 7, 2141-2156, doi:10.5194/gmd-7-21412014, 2014.

de Boer, B., Dolan, A. M., Bernales, J., Gasson, E., Goelzer, H., Golledge, N. R., Sutter, J., Huybrechts, P., Lohmann, G., Rogozhina, I., Abe-Ouchi, A., Saito, F., and van de Wal, R. S. W.: Simulating the Antarctic ice sheet in the late-Pliocene warm period: PLISMIP-ANT, an ice-sheet model intercomparison project, The Cryosphere, 9, 881-903, doi:10.5194/tc-9-8812015, 2015.

DeConto, R. M. and Pollard, D.: Contribution of Antarctica to past and future sea-level rise, Nature, 531, 591-597, doi:10.1038/nature17145, 2016.

Depoorter, M. A., Bamber, J. L., Griggs, J. A., Lenaerts, J. T. M., Ligtenberg, S. R. M., van den Broeke, M. R., and Moholdt, G.: Calving fluxes and basal melt rates of Antarctic ice shelves, Nature, 502, 89-92, doi:10.1038/nature12567, 2013.

Driesschaert, E., Fichefet, T., Goosse, H., Huybrechts, P., Janssens, I., Mouchet, A., Munhoven, G., Brovkin, V., and Weber, S.: Modeling the influence of Greenland ice sheet melting on the Atlantic meridional overturning circulation during the next millennia, Geophys. Res. Lett., 34, 10707, doi:10.1029/2007GL029516, 2007.

Duplessy, J. C., Roche, D. M., and Kageyama, M.: The deep ocean during the last interglacial period, Science, 316, 89-91, doi:10.1126/science.1138582, 2007.

Dutton, A., Carlson, A. E., Long, A. J., Milne, G. A., Clark, P. U., DeConto, R., Horton, B. P., Rahmstorf, S., and Raymo, M. E.: Sea-level rise due to polar ice-sheet mass loss during past warm periods, Science, 349, 1-9, doi:10.1126/science.aaa4019, 2015.

Dutton, A. and Lambeck, K.: Ice Volume and Sea Level During the Last Interglacial, Science, 337, 216-219, doi:10.1126/science.1205749, 2012.

EPICA community members: Eight glacial cycles from an Antarctic ice core, Nature, 429, 623-628, doi:10.1038/Nature02599, 2004

Fretwell, P., Pritchard, H. D., Vaughan, D. G., Bamber, J. L., Barrand, N. E., Bell, R., Bianchi, C., Bingham, R. G., Blankenship, D. D., Casassa, G., Catania, G., Callens, D., Conway, H., Cook, A. J., Corr, H. F. J., Damaske, D., Damm, V., Ferraccioli, F., Forsberg, R., Fujita, S., Gim, Y., Gogineni, P., Griggs, J. A., Hindmarsh, R. C. A., Holmlund, P., Holt, J. W., Jacobel, R. W., Jenkins, A., Jokat, W., Jordan, T., King, E. C., Kohler, J., Krabill, W., Riger-Kusk, M., Langley, K. A., Leitchenkov, G., Leuschen, C., Luyendyk, B. P., Matsuoka, K., Mouginot, J., Nitsche, F. O., Nogi, Y., Nost, O. A., Popov, S. V., Rignot, E., Rippin, D. M., Rivera, A., Roberts, J., Ross, N., Siegert, M. J., Smith, A. M., Steinhage, D., Studinger, M., Sun, B., Tinto, B. K., Welch, B. C., Wilson, D., Young, D. A., Xiangbin, C., and Zirizzotti, A. Bedmap2: improved ice bed, surface and thickness datasets for 
Antarctica, The Cryosphere, 7, 375-393, doi:10.5194/tc-7-3752013, 2013.

Fürst, J. J., Goelzer, H., and Huybrechts, P.: Effect of higher-order stress gradients on the centennial mass evolution of the Greenland ice sheet, The Cryosphere, 7, 183-199, doi:10.5194/tc-7183-2013, 2013.

Goelzer, H., Huybrechts, P., Loutre, M. F., Goosse, H., Fichefet, T., and Mouchet, A.: Impact of Greenland and Antarctic ice sheet interactions on climate sensitivity, Clim. Dynam., 37, 1005-1018, doi:10.1007/s00382-010-0885-0, 2011.

Goelzer, H., Huybrechts, P., Raper, S. C. B., Loutre, M. F., Goosse, H., and Fichefet, T.: Millennial total sea level commitments projected with the Earth system model of intermediate complexity LOVECLIM, Environ. Res. Lett., 7, 045401, doi:10.1088/17489326/7/4/045401, 2012.

Goelzer, H., Huybrechts, P., Loutre, M.-F., and Fichefet, T.: Impact of ice sheet meltwater fluxes on the climate evolution at the onset of the Last Interglacial, Clim. Past, 12, 1721-1737, doi:10.5194/cp-12-1721-2016, 2016.

Golledge, N. R., Menviel, L., Carter, L., Fogwill, C. J., England, M. H., Cortese, G., and Levy, R. H.: Antarctic contribution to meltwater pulse 1A from reduced Southern Ocean overturning, Nat. Commun., 5, 5107, doi:10.1038/ncomms6107, 2014.

Goosse, H. and Fichefet, T.: Importance of ice-ocean interactions for the global ocean circulation: A model study, J. Geophys. Res., 104, 23337-23355, doi:10.1029/1999JC900215, 1999.

Goosse, H., Brovkin, V., Fichefet, T., Haarsma, R., Huybrechts, P., Jongma, J., Mouchet, A., Selten, F., Barriat, P.-Y., Campin, J.M., Deleersnijder, E., Driesschaert, E., Goelzer, H., Janssens, I., Loutre, M.-F., Morales Maqueda, M. A., Opsteegh, T., Mathieu, P.-P., Munhoven, G., Pettersson, E. J., Renssen, H., Roche, D. M., Schaeffer, M., Tartinville, B., Timmermann, A., and Weber, S. L.: Description of the Earth system model of intermediate complexity LOVECLIM version 1.2, Geosci. Model Dev., 3, 603-633, doi:10.5194/gmd-3-603-2010, 2010.

Grant, K. M., Rohling, E. J., Bar-Matthews, M., Ayalon, A., Medina-Elizalde, M., Ramsey, C. B., Satow, C., and Roberts, A. P.: Rapid coupling between ice volume and polar temperature over the past 150000 years, Nature, 491, 744-747, doi:10.1038/nature11593, 2012.

Helsen, M. M., van de Berg, W. J., van de Wal, R. S. W., van den Broeke, M. R., and Oerlemans, J.: Coupled regional climate-icesheet simulation shows limited Greenland ice loss during the Eemian, Clim. Past, 9, 1773-1788, doi:10.5194/cp-9-1773-2013, 2013.

Holden, P. B., Edwards, N. R., Wolff, E. W., Lang, N. J., Singarayer, J. S., Valdes, P. J., and Stocker, T. F.: Interhemispheric coupling, the West Antarctic Ice Sheet and warm Antarctic interglacials, Clim. Past, 6, 431-443, doi:10.5194/cp-6-431-2010, 2010.

Huybrechts, P.: Sea-level changes at the LGM from ice-dynamic reconstructions of the Greenland and Antarctic ice sheets during the glacial cycles, Quaternary Sci. Rev., 21, 203-231, doi:10.1016/S0277-3791(01)00082-8, 2002.

Huybrechts, P. and de Wolde, J.: The dynamic response of the Greenland and Antarctic ice sheets to multiple-century climatic warming, J. Climate, 12, 2169-2188, 1999.

Huybrechts, P., Goelzer, H., Janssens, I., Driesschaert, E., Fichefet, T., Goosse, H., and Loutre, M. F.: Response of the Greenland and Antarctic Ice Sheets to Multi-Millennial Greenhouse Warming in the Earth System Model of Intermediate Complexity LOVECLIM, Surv. Geophys., 32, 397-416, doi:10.1007/s10712-0119131-5, 2011.

Janssens, I. and Huybrechts, P.: The treatment of meltwater retention in mass-balance parameterizations of the Greenland ice sheet, Ann. Glaciol., 31, 133-140, 2000.

Kopp, R. E., Simons, F. J., Mitrovica, J. X., Maloof, A. C., and Oppenheimer, M.: Probabilistic assessment of sea level during the last interglacial stage, Nature, 462, 863-867, doi:10.1038/nature08686, 2009.

Kopp, R. E., Simons, F. J., Mitrovica, J. X., Maloof, A. C., and Oppenheimer, M.: A probabilistic assessment of sea level variations within the last interglacial stage, Geophys. J. Int., 193, 711-716, doi:10.1093/gji/ggt029, 2013.

Landais, A., Masson-Delmotte, V., Capron, E., Langebroek, P. M., Bakker, P., Stone, E. J., Merz, N., Raible, C. C., Fischer, H., Orsi, A., Prié, F., Vinther, B., and Dahl-Jensen, D.: How warm was Greenland during the last interglacial period?, Clim. Past, 12, 1933-1948, doi:10.5194/cp-12-1933-2016, 2016.

Lisiecki, L. E. and Raymo, M. E.: A Pliocene-Pleistocene stack of 57 globally distributed benthic delta O-18 records, Paleoceanography, 20, PA1003, doi:10.1029/2004pa001071, 2005.

Loutre, M. F., Fichefet, T., Goosse, H., Huybrechts, P., Goelzer, H., and Capron, E.: Factors controlling the last interglacial climate as simulated by LOVECLIM1.3, Clim. Past, 10, 1541-1565, doi:10.5194/cp-10-1541-2014, 2014.

MacGregor, J. A., Fahnestock, M. A., Catania, G. A., Paden, J. D., Prasad Gogineni, S., Young, S. K., Rybarski, S. C., Mabrey, A. N., Wagman, B. M., and Morlighem, M.: Radiostratigraphy and age structure of the Greenland Ice Sheet, J. Geophys. Res.-Earth, 120, 212-241, doi:10.1002/2014JF003215, 2015.

Masson-Delmotte, V., Schulz, M., Abe-Ouchi, A., Beer, J., Ganopolski, A., González Rouco, J., Jansen, E., Lambeck, K., Luterbacher, J., Naish, T., Osborn, T., Otto-Bliesner, B., Quinn, T., Ramesh, R., Rojas, M., Shao, X., and Timmermann, A.: Information from paleoclimate archives, in: Climate Change 2013: The Physical Science Basis. Contribution of Working Group I to the Fifth Assessment Report of the Intergovernmental Panel on Climate Change, edited by: Stocker, T. F., Qin, D., Plattner, G.K., Tignor, M., Allen, S. K., Boschung, J., Nauels, A., Xia, Y., Bex, V., and Midgley, P. M., Cambridge University Press, Cambridge, United Kingdom and New York, NY, USA, 383-464, 2013.

Masson-Delmotte, V., Steen-Larsen, H. C., Ortega, P., Swingedouw, D., Popp, T., Vinther, B. M., Oerter, H., Sveinbjornsdottir, A. E., Gudlaugsdottir, H., Box, J. E., Falourd, S., Fettweis, X., Gallée, H., Garnier, E., Gkinis, V., Jouzel, J., Landais, A., Minster, B., Paradis, N., Orsi, A., Risi, C., Werner, M., and White, J. W. C.: Recent changes in north-west Greenland climate documented by NEEM shallow ice core data and simulations, and implications for past-temperature reconstructions, The Cryosphere, 9, 14811504, doi:10.5194/tc-9-1481-2015, 2015.

Mckay, N. P., Overpeck, J. T., and Otto-Bliesner, B. L.: The role of ocean thermal expansion in Last Interglacial sea level rise, Geophys. Res. Lett., 38, L14605, doi:10.1029/2011GL048280, 2011.

Menviel, L., Spence, P., and England, M. H.: Contribution of enhanced Antarctic Bottom Water formation to Antarctic warm events and millennial-scale atmospheric $\mathrm{CO} 2$ increase, Earth 
Planet. Sc. Lett., 413, 37-50, doi:10.1016/j.eps1.2014.12.050, 2015.

Merz, N., Born, A., Raible, C. C., Fischer, H., and Stocker, T. F.: Dependence of Eemian Greenland temperature reconstructions on the ice sheet topography, Clim. Past, 10, 1221-1238, doi:10.5194/cp-10-1221-2014, 2014.

Merz, N., Born, A., Raible, C. C., and Stocker, T. F.: Warm Greenland during the last interglacial: the role of regional changes in sea ice cover, Clim. Past, 12, 2011-2031, doi:10.5194/cp-122011-2016, 2016.

NEEM community members: Eemian interglacial reconstructed from a Greenland folded ice core, Nature, 493, 489-494, doi:10.1038/nature11789, 2013.

Nowicki, S. M. J., Payne, T., Larour, E., Seroussi, H., Goelzer, H., Lipscomb, W., Gregory, J., Abe-Ouchi, A., and Shepherd, A.: Ice Sheet Model Intercomparison Project (ISMIP6) contribution to CMIP6, Geosci. Model Dev. Discuss., doi:10.5194/gmd-2016105, in review, 2016.

Opsteegh, J. D., Haarsma, R. J., Selten, F. M., and Kattenberg, A.: ECBILT: a dynamic alternative to mixed boundary conditions in ocean models, Tellus, 50, 348-367, doi:10.1034/j.16000870.1998.t01-1-00007.x, 1998.

Pedersen, R. A., Langen, P. L., and Vinther, B. M.: Greenland during the last interglacial: the relative importance of insolation and oceanic changes, Clim. Past, 12, 1907-1918, doi:10.5194/cp-121907-2016, 2016.

Pollard, D. and DeConto, R. M.: Modelling West Antarctic ice sheet growth and collapse through the past five million years, Nature, 458, 329-332, doi:10.1038/nature07809, 2009.

Pollard, D., DeConto, R. M., and Alley, R. B.: Potential Antarctic Ice Sheet retreat driven by hydrofracturing and ice cliff failure, Earth Planet. Sc. Lett., 412, 112-121, doi:10.1016/j.epsl.2014.12.035, 2015.

Robinson, A., Calov, R., and Ganopolski, A.: Greenland ice sheet model parameters constrained using simulations of the Eemian Interglacial, Clim. Past, 7, 381-396, doi:10.5194/cp-7-381-2011, 2011.

Robinson, A. and Goelzer, H.: The importance of insolation changes for paleo ice sheet modeling, The Cryosphere, 8, 14191428, doi:10.5194/tc-8-1419-2014, 2014.

Rohling, E. J., Foster, G. L., Grant, K. M., Marino, G., Roberts, A. P., Tamisiea, M. E., and Williams, F.: Sea-level and deep-seatemperature variability over the past 5.3 million years, Nature, 508, 477-482, doi:10.1038/nature13230, 2014.

Shakun, J. D., Lea, D. W., Lisiecki, L. E., and Raymo, M. E.: An 800-kyr record of global surface ocean delta O-18 and implications for ice volume-temperature coupling, Earth Planet. Sc. Lett., 426, 58-68, doi:10.1016/j.eps1.2015.05.042, 2015.

Sjolte, J. and Hoffmann, G.: Modelling stable water isotopes in monsoon precipitation during the previous interglacial, Quaternary Sci. Rev., 85, 119-135, doi:10.1016/j.quascirev.2013.12.006, 2014.
Steen-Larsen, H. C., Masson-Delmotte, V., Hirabayashi, M., Winkler, R., Satow, K., Prié, F., Bayou, N., Brun, E., Cuffey, K. M., Dahl-Jensen, D., Dumont, M., Guillevic, M., Kipfstuhl, S., Landais, A., Popp, T., Risi, C., Steffen, K., Stenni, B., and Sveinbjörnsdottír, A. E.: What controls the isotopic composition of Greenland surface snow?, Clim. Past, 10, 377-392, doi:10.5194/cp-10-377-2014, 2014.

Steig, E. J., Huybers, K., Singh, H. A., Steiger, N. J., Ding, Q. H., Frierson, D. M. W., Popp, T., and White, J. W. C.: Influence of West Antarctic Ice Sheet collapse on Antarctic surface climate, Geophys. Res. Lett., 42, 4862-4868, doi:10.1002/2015GL063861, 2015.

Stocker, T. F.: The Seesaw Effect, Science, 282, 61-62, doi:10.1126/science.282.5386.61, 1998.

Stone, E. J., Lunt, D. J., Annan, J. D., and Hargreaves, J. C.: Quantification of the Greenland ice sheet contribution to Last Interglacial sea level rise, Clim. Past, 9, 621-639, doi:10.5194/cp-9621-2013, 2013.

Swingedouw, D., Fichefet, T., Huybrechts, P., Goosse, H., Driesschaert, E., and Loutre, M. F.: Antarctic ice-sheet melting provides negative feedbacks on future climate warming, Geophys Res. Lett., 35, L17705, doi:10.1029/2008GL034410, 2008.

Thompson, W. G., Curran, H. A., Wilson, M. A., and White, B.: Sea-level oscillations during the last interglacial highstand recorded by Bahamas corals, Nat. Geosci., 4, 684-687, doi:10.1038/ngeo1253, 2011.

Turney, C. S. M. and Jones, R. T.: Does the Agulhas Current amplify global temperatures during super-interglacials?, J. Quaternary Sci., 25, 839-843, doi:10.1002/jqs.1423, 2010.

van de Berg, W. J., van den Broeke, M., Ettema, J., van Meijgaard, E., and Kaspar, F.: Significant contribution of insolation to Eemian melting of the Greenland ice sheet, Nat. Geosci., 4, 1-5, doi:10.1038/ngeo1245, 2011.

van de Berg, W. J., van den Broeke, M. R., van Meijgaard, E., and Kaspar, F.: Importance of precipitation seasonality for the interpretation of Eemian ice core isotope records from Greenland, Clim. Past, 9, 1589-1600, doi:10.5194/cp-9-1589-2013, 2013.

Vernon, C. L., Bamber, J. L., Box, J. E., van den Broeke, M. R., Fettweis, X., Hanna, E., and Huybrechts, P.: Surface mass balance model intercomparison for the Greenland ice sheet, The Cryosphere, 7, 599-614, doi:10.5194/tc-7-599-2013, 2013.

Yau, A. M., Bender, M. L., Robinson, A., and Brook, E. J.: Reconstructing the last interglacial at Summit, Greenland: Insights from GISP2, P. Natl. Acad. Sci. USA, 113, 9710-9715, doi:10.1073/pnas.1524766113, 2016.

Zweck, C. and Huybrechts, P.: Modeling of the northern hemisphere ice sheets during the last glacial cycle and glaciological sensitivity, J. Geophys. Res, 110, D07103, doi:10.1029/2004JD005489, 2005. 